\title{
Fostering job search among older workers: the case for pension reform
}

\author{
J. Ignacio García-Pérez ${ }^{1,2}$ and Alfonso R. Sánchez-Martín ${ }^{1 *}$
}

\author{
*Correspondence: \\ arsanmar@upo.es \\ 1 Department of Economics, \\ Universidad Pablo de Olavide, Ctra \\ de Utrera Km 1, 41013 Seville, Spain \\ Full list of author information is \\ available at the end of the article
}

\begin{abstract}
Employment rates among senior workers (aged 55 or over) in southern Europe are among the lowest in OECD economies. Spain is a paradigmatic example, with high unemployment rates and very low workforce reentry rates for unemployed workers. Poor demand is typically blamed for this problem, but the interaction of pension rules and unemployment insurance may also play an important role in this outcome. Generous unemployment benefits, lax search requirements for the unemployed and strong early retirement penalties imposed on "regular" retirees effectively create an alternative path to early retirement.

In this paper, we explore this alternative path quantitatively. We develop a model of job search and retirement behavior, calibrate it to the specificities of the Spanish case and verify its empirical validity in a large administrative dataset of employment histories. We then explore the effectiveness of pension reform in increasing the labor supply and overall welfare. We link early retirement penalties to the age at which an individual stops paying contributions. This reform removes the incentives to remain unemployed without searching and thus encourages individuals to either retire or actively engage in job seeking. The reform also leads to significant welfare losses, especially among the previously non-participating unemployed who are close to the early retirement age; however, the reform also raises sufficient additional resources that public authorities can use to compensate all affected workers.
\end{abstract}

JEL codes: J64; J68; J26

Keywords: Unemployment; Retirement; Pension reform; Search models

\section{Introduction}

The Spanish labor market has a longstanding tradition of not being particularly friendly to elderly workers. At the time of this writing, the employment rates of workers aged 50 to 64 are among the lowest in OECD countries $(52 \%$ in Spain vs. $62 \%$ in the EU-15). Rates have been low for a long period of time, even after the sharp improvement in employment recorded in the last cyclical expansion of 2000-2008 (the employment rate for those aged 50-59 rose from $52 \%$ in Q1-2000 to $63 \%$ in Q2-2008). This tendency was abruptly halted during the Great Recession and the subsequent sovereign debt crisis, which has sent the unemployment rate for this age range skyrocketing to more than $21 \%$ (from $5.3 \%$ in Q3-2007). For older workers, unemployment is supposed to be a transitory stage in the process of returning to the labor force or before a permanent withdrawal from

(C) 2015 García-Pérez and Sánchez-Martín. Open Access This article is distributed under the terms of the Creative Commons Attribution 4.0 International License (http://creativecommons.org/licenses/by/4.0/), which permits unrestricted use, distribution, and reproduction in any medium, provided you give appropriate credit to the original author(s) and the source, provide a link to the Creative Commons license, and indicate if changes were made. The Creative Commons Public Domain Dedication waiver (http://creativecommons.org/publicdomain/zero/1.0/) applies to the data made available in this article, unless otherwise stated. 
the job market. However, the incidence of long-term unemployment $(+1$ year) is particularly high in this group ( $46.5 \%$ vs. $37.8 \%$ in the $16-39$ age group), nearly always ending in total withdrawal from the labor force. Indeed, the observed reentry rates are remarkably low (in Spain, the quarterly reemployment hazard is less than $13 \%$ in the 55-59 age range and a meager $1.5 \%$ in the 60-65 range). To complete the overall picture, note that a small proportion of the unemployed declare that they are actively searching for a new position. ${ }^{1}$

Several factors have been invoked to explain this state of affairs. On the one hand, demand-side considerations appear to play a major role, with Spanish corporations reluctant to attract older unemployed individuals back to the workforce. A number of reasons (ranging from the rigidity of remuneration practices to large productivity deficits compared with their younger workmates) are usually mentioned to explain this behavior. On the other hand, searching and retraining are assumed to generate especially high welfare costs for workers of advanced age. In response, legislators and policy makers have been quick to provide particular protection for those workers (in the form of early retirement programs and, in some cases, tailor-made unemployment insurance (UI) schemes for older workers). As a result, benefits for unemployed individuals over the age of 50 are typically higher or can be drawn for longer periods than benefits for younger unemployed individuals. Furthermore, the conditions regarding availability for work and job-seeking are often relaxed. Moreover, the unemployed are subject to regular (and sometimes ad hoc) pension regulations. This scheme opens a new set of opportunities for them, as it clearly sets the choices of the unemployed approaching retirement apart from the choices made by their younger counterparts (see Tatsiramos (2009) for an analysis of the behavior of young unemployed workers). In Spain (as in other EU countries), loopholes in the rules make it feasible for older unemployed individuals to escape early retirement penalties while enjoying the income protection of unemployment benefits (but without suffering the pains involved in the job search process). In other words, strategic individuals and corporations can use unemployment and pension rules to transfer the costs of quasi-voluntary early retirement to the general population. ${ }^{2}$ Such practices have clear direct costs for public finances (leading to higher taxation) as well as important opportunity costs in terms of wasted or inefficiently allocated resources. In Europe, which is struggling to regain competitiveness and is threatened by population aging and soaring pension costs, these considerations are having an increasing influence on the decisions of national governments and on the recommendations of the European Commission. ${ }^{3}$

The goal of this paper is to uncover the relative contribution of bad institutional incentives versus poor labor demand to the meager reemployment rates of Spanish workers aged 55 and over. More precisely, we aim to achieve the following: (i) to quantify the extension of the opportunistic behavior of the Spanish unemployed (those who fail to engage in a real search effort while enjoying the income protection of the unemployment program) and (ii) to explore feasible changes aiming to improve incentives in the current policy design. In particular, we attempt to measure their welfare impact and financial cost on the joint system of unemployment and old-age protection. To answer these questions, we build, calibrate and simulate a model of optimal search and retirement behavior adapted to the Spanish institutional environment. ${ }^{4}$ After testing the model's ability to match the basic empirical patterns (in a large sample of administrative records from the Spanish Social Security System for the 2002-2008 period), we use it to simulate the reactions to alternative institutional environments. First, we consider a theoretical 
environment in which the fiscal authorities can enforce the search request as a prerequisite for unemployment insurance. We then explore a real-world pension reform aimed at eliminating the incentive for opportunistic use of the UI system: we classify individuals as early retired immediately after they stop paying contributions (rather than when they first claim the pension benefit). This approach should stimulate the self-selection of workers into either early retirement or job search, even in a world of imperfect observability.

We find that our stylized model of search and retirement can very accurately reproduce the age patterns of labor supply and reentry wages in Spain. The parameters that deliver a good empirical match reveal an environment with rather high search costs for individuals and poor labor demand conditions for older workers (summarized in relatively small average wage offers and a sizable chance of failing to receive any offer at all). The model predicts widespread voluntary non-participation by the older unemployed as a rational response to such an unfavorable labor market (given the Spanish institutional environment). Our first policy experiment illustrates the opportunistic nature of this behavior: we find a strong increase in labor supply in the world where search requirements are effectively implemented. This outcome leads to large savings in the net pension liabilities of the pension system. Our main experiment, however, is more relevant for real-world policy makers. Our feasible reform achieves appreciable increases in the labor supply and sizable reductions in the implicit liabilities of the pension system. These financial gains are sufficiently large to fully compensate for all the welfare losses inflicted by the reform. Inducing search efforts among unemployed workers close to retirement is (theoretically) cost-effective in the Spanish case. ${ }^{5}$ However, even if the change is not strictly Paretoimproving, policy makers could judge the gains in efficiency as sufficiently large to lead to an overall improvement in social welfare.

The structure of this paper is as follows. Section 2 discusses the relevance of the Spanish case, its public institutions and the main empirical patterns. The theoretical model is discussed at length in section 3, including a discussion of the model calibration and a review of its quantitative performance. Our simulation experiments, including our policy reform proposal, are presented in section 4. Finally, section 5 presents our overall conclusions. Three appendices provide further details on the workings of the model (Appendix A), the reference sample (Appendix B) and pension cost calculations (Appendix C).

\section{The Spanish case}

This paper focuses on the impact of pension and unemployment rules on the labor supply in Spain. Even within the context of today's troubled European labor markets, the Spanish situation stands out. Compared with its Europeans peers, Spain's unemployment rate is much higher, and its employment rates for workers close to retirement are lower (approximately $45 \%$ vs. more than $57 \%$ in the UK or Germany). ${ }^{6}$ These figures are expected to worsen in the future, given the dramatic trend toward population aging in Spain. ${ }^{7}$ The case of Spain is also interesting because it is relatively easy to mimic its relevant economic institutions in a tractable economic model. Its institutions can be modeled relatively easily because public pensions and unemployment benefits are the main sources of income for retirees (with private pensions or housing wealth playing a largely unimportant role) and because health insurance is also provided universally by the public sector. Furthermore, public regulations provide well-defined and easily quantifiable incentives. ${ }^{8}$ 
The crux of our argument is that, formally, early retirement (i.e., claiming pension benefits before the Normal Retirement Age, NRA, of 65) implies a severe permanent reduction in pension benefits (between 6 and $8 \%$ per annum, depending on personal circumstances). However, the system also allows for an unofficial route into early retirement through UI. ${ }^{9}$ The latter includes a very generous contributive benefit for up to two years, followed by a small unemployment subsidy available until the pension is drawn. This system creates a strong incentive to remain unemployed without searching for work. We can easily find traces of this behavior in the review of the basic empirical patterns of older workers in Spain (section 2.2). First, we describe the two basic institutions affecting older workers' decisions in the next section.

\subsection{Institutional environment}

In this section, we provide a basic overview of the main features of the Spanish Unemployment Insurance system. These elements are reproduced in our model in section 3. A more detailed description of the intricacies of the system can be found in Rebollo-Sanz (2012). UI benefits in Spain ("prestación contributiva", $b(\pi, h)$ ) are linked to workers' previous earnings, $\pi$, and to the duration of the unemployment spell, $h$. These benefits can be received at any age up to the statutory NRA. These benefits are computed as a percentage of the previous wage, with this percentage (the replacement rate) decreasing with the duration of the unemployment spell ( 65 and $60 \%$ for the first and second year, respectively). However, this proportionality between benefits and previous earnings is disrupted by the existence of legal limits on minimum and maximum annual payments, $b_{\min }$ and $b_{\max }$, respectively. When the length of the unemployment spell exceeds two years, the system provides a means-tested unemployment assistance benefit ("subsidio de desempleo") that may be received up until retirement. This subsidy is available for unemployed individuals aged 52 or over who are eligible for a retirement pension (except for their age) provided that their income is below a quite restrictive amount. Historically, the size of this unemployment subsidy $b_{\min }^{s}$ has been approximately $75 \%$ of the minimum wage. As in most EU member states, the system includes a set of sanctions to be imposed on the recipients of benefits with an insufficient attachment to the labor market. In practice, however, these sanctions are largely overlooked (Peters et al. (2004), section 6.2). In addition to supporting the disposable income of the unemployed, the Unemployment Public Office (INEM) protects their future pension income by paying payroll contributions on their behalf to the Social Security system. These contributions are a fixed proportion of the individual "pensionable wage" (the part of labor income that is used to determine the future pension benefit). In the system in place over the time span covered by our data (2002-2008), INEM contributes the full previous wages of those unemployed with a duration of less than two years $(h \leq 2)$ and $125 \%$ of the minimum contribution, $\min C$, in the case of a longer duration.

Regarding the pension system, we focus here on the "General Regime" of the system, which is also fairly standard relative to Spain's European counterparts. ${ }^{10}$ We focus on the set of regulations that form the core of the system. Note, however, that after 1997, a sequence of small changes have been progressively introduced (ending in the 2011-2013 reforms, which include quite substantial modifications of the parameters and the working of the system). For example, the legal Early Retirement Age (ERA) for cohorts after 1967 is delayed from 60 to 61 and can be accessed only after a 6-month unemployment spell. 
As described in section 2.2, we avoid this institutional non-stationarity by focusing on behavior between 2002 and 2008 (i.e., by focusing on cohorts born between 1937 and 1953). There remain some time-varying parameters in that period, but its quantitative importance is minor.

The Spanish system is a pure pay-as-you-go scheme in which contributions are a fixed proportion of covered earnings (roughly, total gross labor earnings excluding payments for overtime work and lying within an annually legislated maximum, $C_{\max }$, and minimum, $C_{\text {min }}$, that vary based on broadly defined professional categories). An individual's entitlement to an old-age pension requires at least 15 years of contributions (a minimum of two years must be in the eight years immediately preceding retirement) and is conditional on having completely withdrawn from the labor force. During the time interval covered by our analysis, the NRA was 65 , but a pension could be claimed as early as $60 .{ }^{11}$ When eligibility conditions are met, the annual individual benefit is computed as follows:

1. First, an individual-specific component $\tilde{B}$ linked to the worker's age, $\tau$, and previous earnings, $\hat{w}$, is calculated. Formally, $\tilde{B}$ is the product of an age-dependent replacement rate, $\mu(\tau)$, and the worker's accrued pension rights, $\hat{w}$. The replacement rate is a linear function of the retirement age: ${ }^{12}$

$$
\mu(\tau)= \begin{cases}\mu_{0}+\mu_{1}(\tau-\mathrm{ERA}) & \mathrm{ERA} \leq \tau<\mathrm{NRA}-1 \\ 1+\mu_{1}^{+65}(\tau-\mathrm{NRA}) & \mathrm{NRA} \leq \tau\end{cases}
$$

Hence, there is an annual penalty of $\mu_{1}$ percentage points for early retirement and a bonus of $\mu_{1}^{+65}$ for each year after the NRA in which retirement is postponed. The accrued pension rights, $\hat{w}$, are based on a monthly moving average of covered labor earnings in the $D$ years immediately before retirement: $\hat{w}_{\tau}=\frac{1}{D} \sum_{i=1}^{D} w_{\tau-i}{ }^{13}$

2. The strict proportionality between pensions and previous individual income is disrupted by making the effective initial benefit, $B(\hat{w}, \tau)$, subject to a pair of annually determined minimum and maximum payments:

$$
B(\hat{w}, \tau)=\left\{\begin{array}{cl}
B_{\min } & \text { if } \tilde{B}(\hat{w}, \tau)<B_{\text {min }} \\
\tilde{B}(\hat{w}, \tau) & \text { if } B_{\min } \leq \tilde{B}(\hat{w}, \tau) \leq B_{\max } \\
B_{\max } & \text { if } B_{\max }<\tilde{B}(\hat{w}, \tau)
\end{array}\right.
$$

3. Finally, pension payments after retirement increase with the retail price index, keeping $B(\hat{w}, \tau)$ constant in real terms throughout the pensioner's life.

\subsection{Empirical evidence}

In this paper, we attempt to uncover the link between the set of rules described above and the observed behavior of older workers in Spain. Some well-established empirical regularities strongly hint at a deep connection between pension/unemployment rules and observed labor choices. For example, in our calibration dataset (Muestra Continua de Vidas Laborales, referred to henceforth as MCVL), more than $55 \%$ of withdrawals from the labor force involve the use of the UI system, with standard direct transitions from employment into retirement. Furthermore, reemployment rates after age 50 are extremely low. As mentioned in the introduction, the quarterly reemployment hazard in our dataset is less than $13 \%$ for workers in the 55-59 age range and $1.5 \%$ for those in the $60-65$ bracket. The self-declared search intensity of those workers is also remarkably weak. 
Figure 1 presents interesting evidence regarding the level of sensitivity to the incentives provided by institutions. This figure displays the observed behavior of Spanish workers conditional on the age of separation from the last job. The right-hand side of the figure shows workers entitled to both UI contributory benefits and unemployment subsidies, while workers on the left-hand side are covered only by the initial UI contributory benefits. ${ }^{14}$ We find that workers who are made redundant in their mid-fifties (up to 58) tend to retire at 60 , the ERA, after very long unemployment spells. For example, those who start their unemployment spell at age 54-55 (i.e., within 5 to 6 years of the ERA) retire after being unemployed for 54 to 74 months. This pattern is largely independent of the availability of unemployment subsidies. By contrast, the behavior of workers who lose their jobs later is strikingly different. Those without subsidies limit their use of the unemployment program to the period covered by contributive benefits and consequently retire in large numbers after only 24 months. On the contrary, those people covered by subsidies remain unemployed for much longer, which causes them to avoid early retirement penalties.

These findings highlight the potential impact of the institutional design on individual workers' incentives to search for a job and/or to retire. These institutions may discourage searching in some unemployed workers and may even foster voluntary redundancies in some groups of employed workers. Exploring the latter behavior is especially difficult, as it involves both the interests of workers and those of their employers. In this paper, we focus on individual choices and thus concentrate our efforts on the search behavior of the unemployed. ${ }^{15}$

\subsubsection{Sample selection}

The empirical evidence comes from the MCVL Spanish administrative dataset, which includes information on the complete labor histories of more than one million Spanish workers. In this paper, we focus on a relatively narrow subsample selected to guarantee that the economic incentives of individuals are clearly identified. Namely, we consider only males aged 55 years or older, affiliated with the General Regime of the Spanish Social Security System who are entitled to receive contributory UI benefits and pensions upon retirement. These individuals can be either employed or unemployed. ${ }^{16}$ This sample is composed of 21,902 individuals with 23,763 unemployment spells $(21.1 \%$ ending in a new job and $62.6 \%$ in a transition to retirement, with the remainder being right-censored unemployment spells). For unemployed individuals returning to a new job, the average
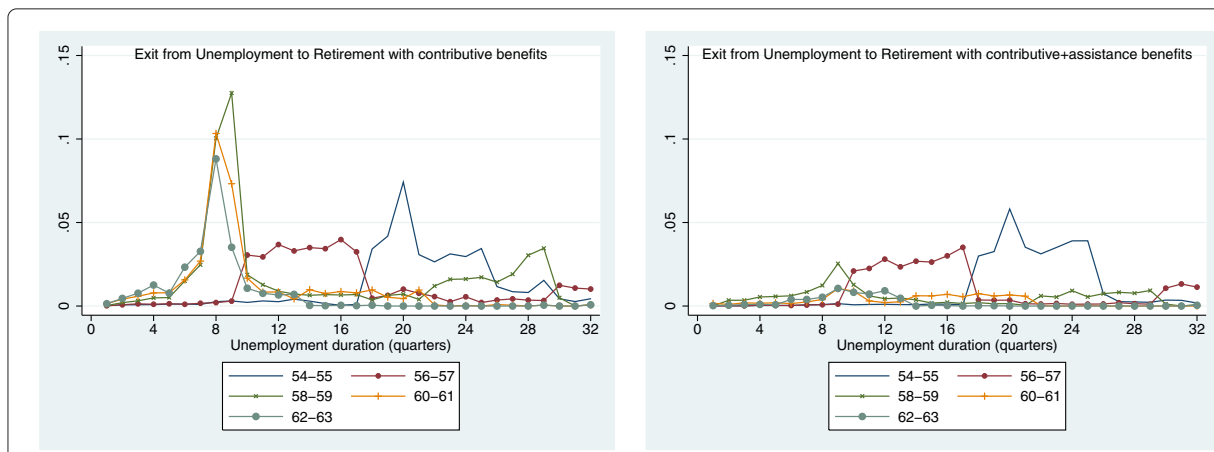

Fig. 1 Differences in retirement hazards depending on the age of dismissal and UI coverage 
unemployment duration is 16.2 months, and their average reentry wages of 1,226 euros imply a $10 \%$ decrease relative to their previous wages $(1,358$ euros, on average). The average duration is longer, approximately 25.7 months, for those who exit to retirement and much longer for those in a right-censored unemployment spell (46.7 months). A complete description of the database, along with a detailed reduced-form econometric analysis, can be found in García-Pérez et al. (2013).

\subsubsection{Main empirical regularities}

Age, unemployment spell duration and the size of the accrued pension rights emerge as the fundamental predictors of behavior, as shown in Fig. 2, which provides a visual summary of the main behavioral regularities in the data. Each graph has age on the horizontal axis and two lines corresponding either to a partition of the sample according to the duration of the unemployment spell $(h)$ (on the left-hand panels) or to the size of the accrued pension rights, $\hat{w}$ (on the right-hand panels). The blue continuous line corresponds to short unemployment spells (under 20 months) or to small accumulated pension rights (below the $1 / 3$ percentile of the overall empirical distribution). The green dashed line corresponds to long unemployment spells (more than 20 months) or to large accumulated pension rights (above the $2 / 3$ percentile of the distribution). The main empirical patterns can be summarized as follows:

Retirement depends heavily on age, pension rights and, above all, unemployment duration (see the top panels in Fig. 2). Although the importance of the first two elements
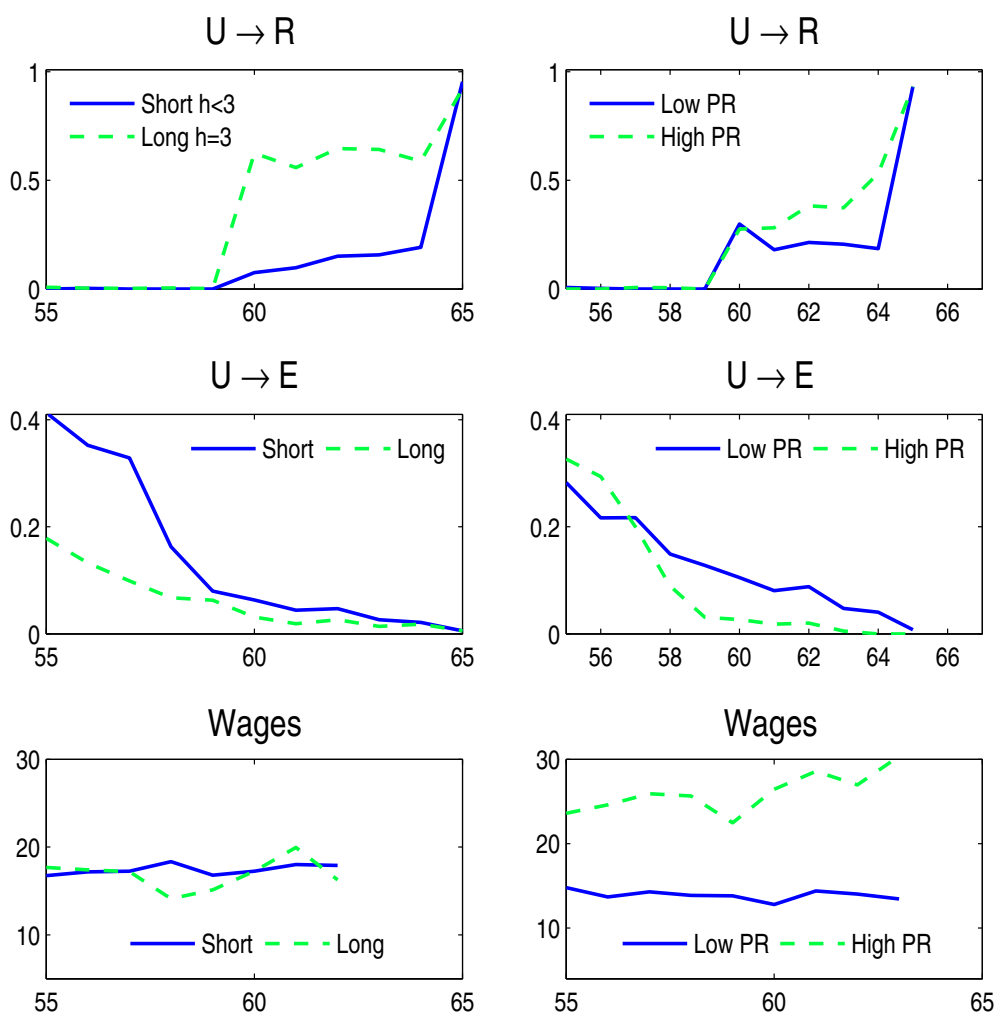

Fig. 2 Empirical patterns by age. From top to bottom: average retirement hazard $(U \rightarrow R)$, re-entry hazard $(U \rightarrow E)$, and re-entry wages, conditional on (left column) unemployment duration, h, and (right column) accrued pension rights, PR 
has been well documented in the study of transitions starting from employment (e.g., Boldrin et al. (1999) or Jiménez-Martín and Sánchez-Martín (2007)), the relevance of duration has largely been overlooked in previous studies.

Reemployment has a well-documented negative dependence on unemployment duration, with the short-term unemployed showing significantly greater reemployment hazards at all ages considered (see the left-middle panel in Fig. 2). The graphs also illustrate a strong negative dependence on age (less well documented) that is attenuated to some extent after the ERA. Finally, workers with high pension rights reenter employment in much smaller proportions after the age of 58 , but the opposite is observed in the preceding years. ${ }^{17}$

Reentry wages (see the lower panels of Fig. 2) do not show much variation by age or unemployment duration, but they are appreciably greater for workers with large accumulated pension rights.

Finally, it is important to recall from Fig. 1 that being entitled to unemployment subsidies leads to different behavior, particularly with regard to retirement. In particular, workers without the ability to collect unemployment subsidies are strong contributors to the flows of early retirement in the data (at ages 60 and 61).

\section{The model}

Individuals must make some genuinely difficult economic decisions at the end of their professional careers. To choose wisely, they must understand the institutional environment; the present and future state of the economy; and the idiosyncratic uncertainties surrounding their income, health and survival probabilities. Including all relevant factors in a model is currently not feasible. As a first step, we proceed with a very simple model that is designed to capture the basic institutional aspects of the problem and the most important sources of uncertainty faced by both employees and the unemployed. A key simplification is that we consider a group of healthy workers (i.e., ignoring the exit route via disability benefits) and, by focusing on the pre-crisis interval 2002-2008, assume that they operate in an stationary environment (i.e., not considering recent pension reforms). We also leave business cycle considerations for future work. ${ }^{18}$ As a result, we interpret our findings as robust lower-bound estimations of the extension of voluntary unemployment. ${ }^{19}$

We consider individuals who behave as rational utility maximizers endowed with a correct understanding of the economic environment. Such individuals may live up to $T$ years (100 in our baseline calibration), but they are subject to a mortality risk represented at each age $a$ by the set of conditional probabilities of surviving to age $a^{\prime}$, $S_{a}\left(a^{\prime}\right), 55 \leq a<a^{\prime} \leq T$. Both the employed and the unemployed face additional uncertainty related to the labor market. The employed face an age-varying risk of dismissal, $\delta($.), while the unemployed who are seeking jobs are uncertain about the arrival of job offers, $\lambda($.), and their associated wages, $w$. There are no other sources of risk in the model.

Individual preferences are represented by a constant intertemporal discount factor, $\beta$, and by a period utility function $u(y, l)$. Utility is assumed to be increasing with the flow of income $(y)$ and with the amount of leisure $(l)$ associated with the action taken by the individual in the period considered. ${ }^{20}$ The precise functional form of this function is discussed in section 3.2. Individual rationality implies that, starting in their 
early fifties, individuals choose their labor status in each period such that the resulting sequences of income and leisure flows maximize their expected discounted utility $U_{a}=E\left[\sum_{i=a}^{T} \beta^{i-a} u\left(y_{i}, l_{i}\right)\right]$ at each age. The institutional environment is as described in section 2.1, with the exception that we simplify the dynamics of the accrued pension rights, $\hat{w}$ (because reproducing the exact formula in the model implies extreme computational costs). We simply assume that for an individual with a current labor income $w$, the one-year update in pension rights is as follows: ${ }^{21}$

$$
\hat{w}_{\tau+1}=\hat{w}_{\tau}+\frac{w-\hat{w}_{\tau}}{D}
$$

\subsection{Recursive representation of the individual problem: labor states and individual decisions}

As usual with complex life-cycle, stochastic models, we actually work with a recursive formulation of the individual problem in the age range of interest (55 to 68). At the beginning of each period (assumed to represent one year of biological time), individuals may find themselves in one of three mutually exclusive labor states: Employment, Unemployment or Retirement $(E, U, R)$. In our model retirement is a passive state, so we only have to consider the choices of the employed and the unemployed, which are as follows:

- At the beginning of period a, the employed can either remain in work for the rest of the period or retire. The life-cycle utility derived in each case is represented by the worker's value functions $E_{a}^{W}\left(\right.$.) and $E_{a}^{R}($.), respectively. They provide the present, discounted utility derived from the current choice and from behaving optimally in all subsequent periods. The total value of being employed at the beginning of each period (before the current choice is made) is represented by the total value function:

$$
V_{a}^{E}=\operatorname{Max}\left\{E_{a}^{W}, E_{a}^{R}\right\}
$$

- Unemployed workers have three possible courses of action at the beginning of period a: search for a new job, remain unemployed without searching (non-participation) or retire immediately. The life-cycle utility associated with each of those options is represented by the value functions $U_{a}^{S}(), U_{a}^{N}()$ and $U_{a}^{R}()$. The total value of starting a period as unemployed is:

$$
V_{a}^{U}=\operatorname{Max}\left\{U_{a}^{S}, U_{a}^{N}, U_{a}^{R}\right\}
$$

The following paragraphs review the optimal choices in each labor state and the construction of their associated value functions.

\subsubsection{Labor choices among unemployed workers}

The main focus of our modeling effort in this paper is the behavior of the unemployed. As indicated above, a worker starting a period as unemployed can retire, search for a new job or remain unemployed without searching. The economic value of each of these options is as follows:

1. Retirement Our model treats retirement as an absorbing state (which is roughly in line with the very low employment rate observed among Spanish pensioners). Individuals take no further actions in this state and simply collect the pension benefit $B$ and enjoy the full allocation of their time endowment, $\bar{l}$, to leisure. Thus, the only personal information needed to compute the economic value of this 
option is the accrued pension rights $\hat{w}$ at the beginning of the period. The associated value function is:

$$
U_{a}^{R}(\hat{w})=\sum_{i=a}^{T} \beta^{i-a} S_{a}(i) u(B(\hat{w}, a), \bar{l})
$$

where $B(\hat{w}, a)$ is computed according to the Spanish institutional rules (eq. (1) and (2)). We only consider retirement at ages equal to or above the ERA (as a result of our extreme borrowing constraints assumption).

2. Non-participation (i.e., inactivity while in the UI system) In accordance with the empirical evidence presented in section 2.2, we allow the unemployed to choose inactivity while remaining in the UI program. By proceeding in this manner, the unemployed avoid all the costs associated with an active labor search. This comes at the price of forgoing any chance of receiving a job offer in the immediately ensuing period. To compute the current unemployment benefit, $b$, we now need to store the value of the wage in the previous employment spell, $\pi$, and the duration of the current unemployment spell in years, $h$. We also need to keep track of the accumulated pension rights, $\hat{w}$, to compute the value of future retirement. Formally, the value of the inactivity choice at age a is:

$$
U_{a}^{N}(\pi, \hat{w}, h)=u(b(\pi, h), \bar{l})+\beta_{a+1} V_{a+1}^{U}\left(\pi, \hat{w}^{\prime}, h+1\right)
$$

where $\beta_{a+1}=\beta S_{a}(a+1)$ is the total discounting factor at age a, $V_{a+1}^{U}($.$) is the$ value of starting the following period as unemployed (defined in eq. (5)) and $\hat{w}^{\prime}$ is the future value of the accrued pension rights (updated according to expression (3)). It should be noted that the value of leisure in this state is assumed to be equal to that enjoyed under retirement, $\bar{l}$. We are assuming that our unemployed workers are, therefore, effectively exempted from any job-search requirements labor authorities may impose.

3. Job Search The value of becoming involved in an active job search is represented by $U_{a}^{S}($.$) and depends on the same set of economic characteristics (\pi, \hat{w}, h)$ as in the non-participation state. It is the sum of two factors: (1) the immediate utility of searching $u\left(b(\pi, h), l^{S}\right)$, where we combine the income from the unemployment benefit and a reduced value of leisure $\left(l^{S}<\bar{l}\right)$ that reflects the costs of searching and re-training; and (2) the expected future value from search, EVS:

$$
U_{a}^{S}(\pi, \hat{w}, h)=u\left(b(\pi, h), l^{S}\right)+\beta_{a+1} E V S_{a+1}\left(\pi, \hat{w}^{\prime}, h+1\right)
$$

The general expression of the expected future value is:

$$
\operatorname{EVS}_{a}(\pi, \hat{w}, h)=\lambda(.) E_{w}\left[\operatorname{Max}\left\{V_{a}^{U}(\pi, \hat{w}, h), E_{a}^{W}(w, \hat{w})\right\}\right]+(1-\lambda(.)) V_{a}^{U}(\pi, \hat{w}, h),
$$

where $V_{a}^{U}$ is the value function associated to starting period a as unemployed (eq. (5)) and where the rate of arrival of job offers $\lambda($.$) is a function of age and$ unemployment duration.

The search option is risky because future job offers may involve relatively low wages and (if $\lambda()<$.1 ) they may even fail to materialize altogether. The EVS term captures these two uncertainties, together with the utility value arising in each eventuality. The first of the two sums in EVS captures the expected value of future 
wages once a job offer has materialized, while the second sum captures the residual value when the search effort fails and no job offer is forthcoming. In more detail:

(1) If the offer of a job paying wage $w$ is received, the individual must decide whether to accept or reject it. To find the best choice, the worker compares the expected utility from reemployment at wage $w, E_{a+1}^{W}\left(w, \hat{w}^{\prime}\right)$, to the utility of starting the next period as unemployed $V_{a+1}^{U}\left(\pi, \hat{w}^{\prime}, h+1\right)$. The utility of employment is presented in eq. (11) below. It is considered in expected terms because the size of the wage offer is uncertain at the beginning of the search process. It should be noted that rejecting a job offer will normally result in a depreciation of the value of being unemployed (due to both the reduction in benefits over the course of the unemployment spell and the updating of the accrued pension rights). ${ }^{22}$ As usual in the literature, the job-acceptance decision is summarized, for each possible value of the state variables, by the corresponding Reservation Wage, $\bar{w}_{a}(\pi, \hat{w}, h)$. This is defined as the wage level that makes the unemployed indifferent between employment at that wage or staying unemployed for one more period. Formally:

$$
E_{a}^{W}\left(\bar{w}_{a}(\pi, \hat{w}, h), \hat{w}\right)=V_{a}^{U}(\pi, \hat{w}, h)
$$

(2) If no offer arrives or if the offer received is unacceptable, the associated value is that of staying unemployed one more period, i.e., $V_{a}^{U}(\pi, \hat{w}, h)$. Formally, the ex ante probability of this outcome is $1-\lambda\left(\right.$.) $\left(1-F\left(\bar{w}^{\prime}\right)\right)$, where $\bar{w}^{\prime}$ stands for the next period's reservation wage, $\bar{w}_{a+1}\left(\pi, \hat{w}^{\prime}, h+1\right)$, and $F$ is the cumulative distribution function of future wage offers.

Overall, the optimal choice for the unemployed is found by comparing $U_{a}^{R}, U_{a}^{N}$ and $U_{a}^{S}$, as already indicated in eq. (5).

\subsubsection{Labor choices among employees}

Currently employed workers have a choice between retiring immediately or remaining employed for one more period. In this paper, we do not allow the employed to move into voluntary unemployment. ${ }^{23}$ The value function associated to remaining employed is:

$$
E_{a}^{W}(w, \hat{w})=u\left(w, l^{W}\right)+\beta_{a}\left[(1-\delta(.)) V_{a+1}^{E}\left(w, \hat{w}^{\prime}\right)+\delta(.) V_{a+1}^{U}\left(w, \hat{w}^{\prime}, 1\right)\right]
$$

The current utility depends on the salary and on the amount of leisure left after complying with all the professional activities $\left(l^{W}<\bar{l}\right)$. Future utility is uncertain, as workers face both survival uncertainty and the risk of being fired and starting the next period as unemployed. The risk of dismissal, $\delta($.$) , is an exogenous function of the worker's characteristics.$ We assume constant real wages and update pension rights, $\hat{w}$, as in eq. (3).

The value of retirement at age $a, E_{a}^{R}(\bar{w})$, is formally identical to that in (6) for the case of unemployed workers. Again, we assume that a direct transition into retirement is possible only after the ERA. All in all, the optimal choice for the employee is found by comparing $E_{a}^{W}(w, \hat{w})$ and $E_{a}^{R}(\bar{w})$ as indicated in (4).

The basic properties of the behavior generated by our model (along with its ability to match the observed Spanish data) are discussed in the next section, while the reader interested in a formal exploration of optimal behavior will find a more detailed analysis in Appendix A. 


\subsection{The calibration}

This section describes how we align the theoretical model in the previous section to Spain's economic circumstances during the interval 2002-2008. We follow a calibration approach: First, we assign values to the model unobservable parameters to reproduce some basic stylized facts obtained from our sample. Then, we aggregate the model predictions for each individual in our reference sample and compare the results to their in-sample counterparts (along both calibrated and non-calibrated dimensions). The process is iterated until a satisfactory set of parameters is found.

The model's parameters can be classified into two broad categories depending on the availability of observable empirical counterparts. On the observable side, we have the parameters controlling human longevity, the institutional details of pension and unemployment schemes and the distributions by observable characteristics. The group without direct empirical counterparts includes the parameters of individual preferences and those that control the demand side of the labor market. This second group of parameters is calibrated to reproduce the average age-profiles of re-entry and retirement rates and the accepted wages of individuals re-entering employment. ${ }^{24}$ Exceptionally, the discount factor, $\beta=1 /(1+r)$, and the degree of risk aversion, $\eta$, are set to the standard values found elsewhere in the literature (see Table 2).

\subsubsection{Observable parameters}

We explore the labor behavior of individuals in the 55-68 age range, assuming an annual time-frame for individual choices. The initial distribution of workers by "type" (with and without unemployment subsidies) and according to our state variables (age, unemployment duration, previous wages and accrued pension rights) corresponds to the sample average observed in the 2002-2008 period. ${ }^{25}$ The continuous state variables $(\pi, \hat{w}) \in$ $\Pi \times \hat{W}$ are discretized as part of our numerical procedure. ${ }^{26}$ Survival probabilities are set according to mortality tables provided by INE (Spain's Institute of Statistics) for the sample period. The values of the model's institutional parameters are summarized in Table 1. The unemployment benefit $b$ is set to $65 \%$ of the previous wage during the first year of the unemployment spell, and to $60 \%$ during the second (albeit necessarily ranging between a floor $b_{\text {min }}$ and a ceiling $b_{\max }$ ). For longer spells, workers are divided according to their entitlement to social assistance $\left(b_{\text {min }}^{s}\right)$. Retirement pensions are first available at the age of

Table 1 Institutional non-calibrated parameters: values assigned to observable parameters in the benchmark economy (all nominal amounts are expressed in thousands of 2002 euros)

\begin{tabular}{|c|c|c|c|}
\hline \multicolumn{2}{|l|}{ Pensions } & \multicolumn{2}{|l|}{ Unemployment } \\
\hline Early/Normal Ret. age & $60-65$ & Benefit coverage $h=1$ & 0.65 \\
\hline Annual early ret. penalty, $\mu_{1}$ & 0.07 & Benefit coverage $h=2$ & 0.6 \\
\hline Initial replacement rate, $\mu_{0}$ & 0.65 & & \\
\hline Bonus Post $65, \mu_{1}^{+65}$ & 0.02 & & \\
\hline Maximum pensions, $B_{\max }$ & 26.69 & Maximum benefit, $b_{\max }$ & 10.1 \\
\hline Minimum pensions, $B_{\min }$ & 6.14 & Minimum benefit, $b_{\min }$ & 4.68 \\
\hline Minimum pensions, $B_{\min }^{65}$ & 6.63 & Unemployment subsidy, $b_{\min }^{s}$ & 4.0 \\
\hline Lags in pension formula, $D$ & 15 & & \\
\hline \multicolumn{4}{|c|}{ Social contributions } \\
\hline Pay-roll rate, $\varsigma$ & 0.356 & Minimum contribution, $C_{\min }$ & 7.29 \\
\hline Maximum contribution, $C_{\max }$ & 31.29 & Min. contrib. subsidy, $C_{\min }^{s}$ & 6.2 \\
\hline
\end{tabular}


60 , with an annual early-retirement penalty of $7 \% . \hat{w}$ is computed to approximate a moving average of the 15 years immediately before retirement (according to eq. (3)). A full pension is granted at the NRA of 65 (with a $2 \%$ annual bonus for those that retire after the "legal" age). The minimum and maximum pensions are regularly changed as part of the annual government budget. The average values for the period are reproduced here. Finally, the pension and unemployment systems are financed with a fixed contribution rate of $35.6 \%$ of the covered wage (gross labor income, with a minimum $C_{\min }=7.3$ and a maximum $C_{\text {max }}=29.8$ thousand euros). The covered wage applied to workers receiving the unemployment subsidy is 6,200 euros.

The calibration of the observable parameters is completed with the exogenous dismissal rates $\delta_{a}(w, \hat{w})$. At each age, we make a partition of the sample according to the $1 / 3$ and $2 / 3$ percentiles of the distribution of wages and pension rights. We set the exogenous value of $\delta$ to the empirical value observed in each cell of the partition. The resulting rates range from $3.8 \%$ to $14.6 \%$.

\subsubsection{Unobservable parameters}

Table 2 presents the calibrated preference and labor-market parameters, while Fig. 3 shows the quality of the match between the model and the data resulting from these parameters. Preferences are represented with a discount factor $\beta=1 /(1+r)$ and an additively separable and age-invariant function of income $y$ and labor state, $e$ :

$$
u(y, e)=\frac{[y(1+v(e))]^{1-\eta}}{1-\eta} \quad \text { with } \quad v(e)=\left\{\begin{array}{l}
0 \text { if } e=E \\
l^{S} \text { if } e=S \\
l \text { if } e=(R, N)
\end{array}\right.
$$

$\eta$ measures the curvature of the objective function and $v(e)$ represents the variation, with the labor state, in the value of the time not devoted to labor-market activities. We normalize this value to zero for employees and assume a positive value $(l)$ for nonparticipants and retirees and a smaller one $\left(l^{s}\right)$ for unemployed job seekers (i.e., we parameterize it as an Added Value of Income, AVI). $l^{s}$ is smaller than $l$ to capture the costs associated with the search process, including the cost of re-training and the possible "stigma" cost of remaining unemployed. We take standard values for $\beta$ and $\eta$, while the leisure parameters $l$ and $l^{s}$ are identified from their impact on re-entry rates and accepted wages. $^{27}$

Labor market properties are captured by the job-offer rate $\lambda$ and the associated distribution of offered wages, $F_{w}$. The job-offer arrival rate is assumed to depend on age and on the duration of the unemployment spell:

$$
\lambda_{a}(h)=\lambda_{0} \cdot\left[1-I(h>1) \lambda_{h}\right] \cdot\left[1-I(a>59) \lambda_{a}\right]
$$

Table 2 Values assigned to unobservable parameter in the benchmark economy

\begin{tabular}{llllll}
\hline & \multicolumn{3}{l}{ Preferences } & & Labor Market parameters \\
\hline$\beta$ & 0.97 & Annual discount factor & $\lambda_{0}$ & 0.6 & Base job-offer arrival rate \\
$\eta$ & 2 & Risk aversion & $\lambda_{h}$ & 0.5 & Factor reduction in $\lambda$ due to $h>1$ \\
$\bar{l}$ & 0.3 & Leisure AVI (Retirement) & $\lambda_{a}$ & 0.8 & Factor reduction in $\lambda$ due to $a>59$ \\
$p^{S}$ & 0.0 & Leisure AVI (search) & $\mu$ & 9.7 & Wage offer mean (thousands of 2002 euros) \\
& & $\sigma$ & 8.9 & Wage offer dispersion (std) \\
\hline
\end{tabular}

AVI added value of income 


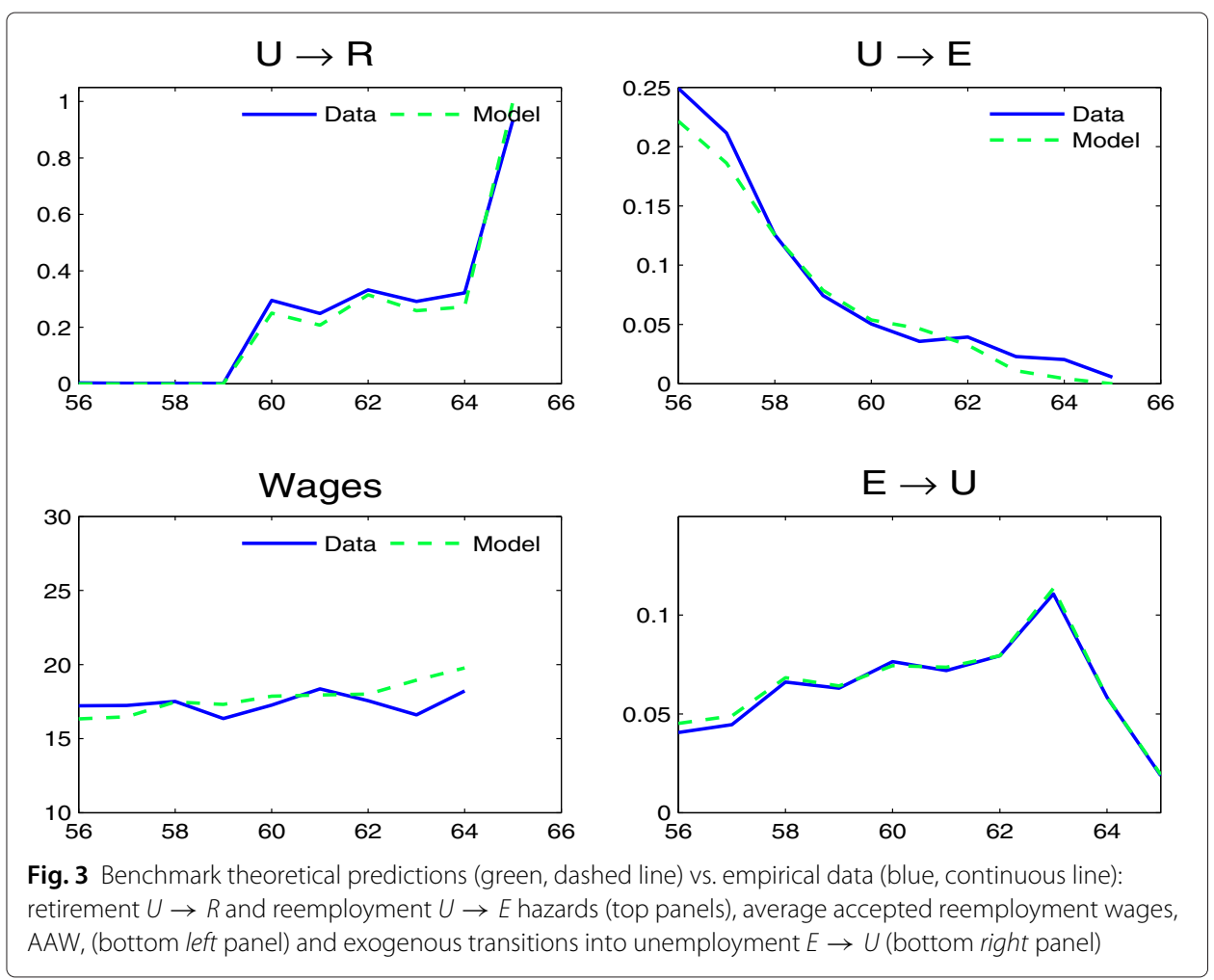

where $I($.$) represents an indicator function of a particular event (being in long-term$ unemployment or older than 59). If we keep $\lambda$ constant in our model, we still predict a drop in re-entry rates as the individual grows older, but the quantitative importance of this process is smaller than in the data. For longer durations, however, the model with fixed $\lambda$ predicts decreasing reservation wages and increasing re-entry rates (in contrast to the evidence). Therefore, to match the process of "hysteresis" observed in the data we must impose a decreasing rate of job-offers from the model's supply side. Finally, the wage associated with each job offer is assumed to be log-normally distributed, with mean $\mu$ and variance $\sigma^{2}$. The parameters with the best empirical fit (Table 2) indicate a fairly large dispersion of offered wages around a very modest average.

All in all, the results of the calibration exercise reveal two important properties of the search process. First and foremost, large search costs are needed to rationalize the observed data. An unemployed person actively searching for a job experiences a relative drop in leisure (vis a vis a similar inactive unemployed person) equivalent to that suffered by a full-time worker (vis a vis a retiree of similar characteristics). Secondly, searching is also considerably risky. The probability of a person who has been unemployed for less than a year receiving an acceptable job offer is between 20 and $30 \%$ (at the age of 55) and drops slightly with age (as the reservation wages increase). At the age of 60 those probabilities fall to the $12-22 \%$ range. For the long-term unemployed, this probability is around $15 \%$. This is partly endogenous (due to relatively high reservation wages), but largely the result of the poor dynamism of the Spanish labor market. 


\subsection{Empirical performance of the model}

Figure 3 assesses the success of our calibration strategy by comparing the data and the model predictions in the three targeted dimensions (reemployment and retirement rates by age and re-entry wages by age). It is apparent that our highly stylized model does remarkably well at reproducing the broad empirical patterns by age. It should be emphasized that the model's ability to capture the general trends in the data is not the result of the exogenous process assumed for the rate of arrival of job offers. The assumed exogenous trends by age and duration help to fit the data quantitatively, but the model reproduces most qualitative patterns even with a constant $\lambda$. Going beyond the calibrated dimensions, Fig. 4 compares the differences in behavior for the long vs. short-term unemployed and for workers in the two tails of the distribution by pension rights. To facilitate the comparison with the data, the graphs are arranged in a similar way to those in Fig. 2. Additionally, Figs. 10 and 11 in Appendix A.2 directly compare the data and predictions for each disaggregated group. There are some quantitative discrepancies, but the model does a generally good job in reproducing the actions of workers of different characteristics. For example, its ability to match the re-entry and retirement patterns of workers with different pension rights is especially outstanding. There are two areas in which the model underperforms: (i) it fails to generate the large differences observed in the data between the re-entry wages of workers with high vs. low pension rights, and (ii) it fails to predict any direct retirement among the short-term unemployed (while there is a small proportion in the data). These two drawbacks (especially the first one) can be addressed to some extent by introducing some additional structure into the model. This extra complexity, however, comes with additional costs in terms of calibration and interpretation
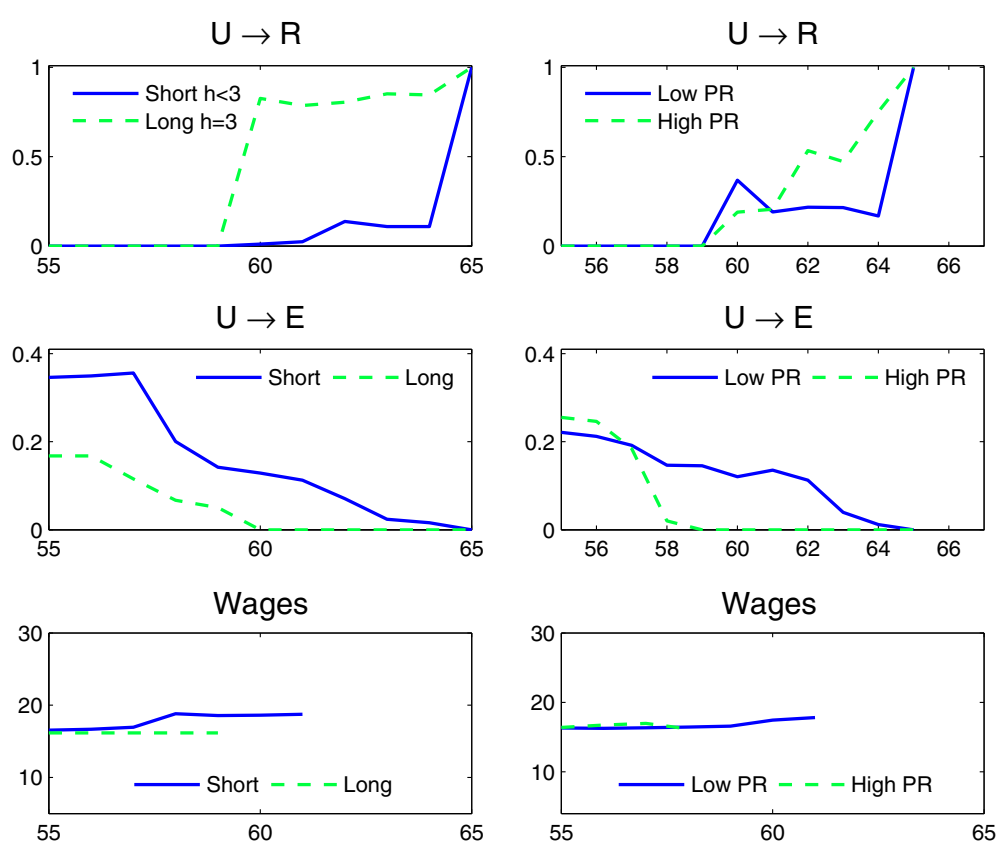

Fig. 4 Model predictions by age. From top to bottom: average retirement hazard $(U \rightarrow R)$, re-entry hazard $(U \rightarrow E)$, and re-entry wages, conditional on (left column) unemployment duration, $h$, and (right column) accrued pension rights, PR 
of the resulting model. ${ }^{28}$ Overall, we find that the benchmark model strikes a good balance between the expected empirical performance and the need for a relatively simple, transparent framework for policy analysis.

\section{Simulation analysis: search and pension reforms in Spain}

Once equipped with a fully calibrated quantitative model, we are in a position to explore the extension of voluntary non-search behavior and the type of workers more likely to be involved in it. These are the tasks assigned to section 4.1. We then ask ourselves to what extent the low reemployment rate is a product of non-search behavior. For a first assessment, we simulate an alternative institutional environment in which this type of behavior is precluded by design (section 4.2). In section 4.3 we then consider a parametric reform of the pension/unemployment rules capable of delivering part of the advantages of a stronger attachment to the labor market. It is in this final environment where we explore the cost-effectiveness of fostering the job search effort.

\subsection{Voluntary non-participation in the benchmark economy}

Table 3 displays the aggregate predictions of our benchmark model for the individuals in our reference sample. The overall non-participation figures can be found under the "NP" heading on the 5th column in the table. More disaggregated results by age are shown in the bottom-right panel of Fig. 5. The numbers are large: the best possible course of action for more than half the individuals (in the 60-64 age range) is to remain unemployed without searching. Before the ERA, this choice is largely confined to long-term unemployed workers (see Fig. 9 in Appendix A.2). However, once the age of 60 has been reached, it becomes more widespread, affecting a majority of those who have been unemployed for less than two years. Only workers with very small pension rights (who prefer to search) and the very long-term unemployed (who opt for retirement) shy away from voluntary non-participation. The non-participation decision of a large part of the unemployed may have major consequences for the financial balance of the public insurance mechanisms. To assess this factor, we calculate the financial burden represented by each of our sample individuals on the combined "pension \& unemployment" system. More precisely, we compute each individual's Net Pension Cost (NPC): the expected discounted value of the flow of future pension and unemployment payments received from the system, net of any

Table 3 Simulation Results: Proportion of workers whose optimal decision is to retire (Ret), Search or stay inactive (NP); reemployment hazard (Reenter, in brackets); NPC1 annuity is the Net Pension Cost in thousands of euros per person; Pension savings is the difference between the NPC1 after each reform and the one in the BASE. EV1 is the welfare change (reformed vs. BASE economy) measured by an Equivalent Variation. Both NPC1 and EV1 apply only to the unemployed with durations of less than 1 year

\begin{tabular}{llllllll}
\hline Economy & Age range & Ret & $\begin{array}{c}\text { Labor supply } \\
\text { Search (Reenter) }\end{array}$ & NP & $\begin{array}{c}\text { NPC1 } \\
\text { Annuity }\end{array}$ & $\begin{array}{c}\text { Pension } \\
\text { savings }\end{array}$ & EV1 \\
\hline BASE & $55-59$ & 0 & $65.0(14.5)$ & 35.0 & & \\
& $60-65$ & 29.2 & $11.6(3.2)$ & 59.2 & 12.92 & \\
\hline PLE: Perfect & $55-59$ & 0 & $83.2(19.7)$ & 16.8 & & \\
Law Enforcement & $60-65$ & 36.6 & $59.1(16.0)$ & 4.3 & 11.71 & 1.21 \\
\hline Separate & $55-59$ & 0 & $70.2(15.9)$ & 29.8 & & & \\
$\mu$ & $60-65$ & 59.3 & $30.6(7.0)$ & 10.1 & 11.38 & 1.54 & 0.90 \\
\hline
\end{tabular}




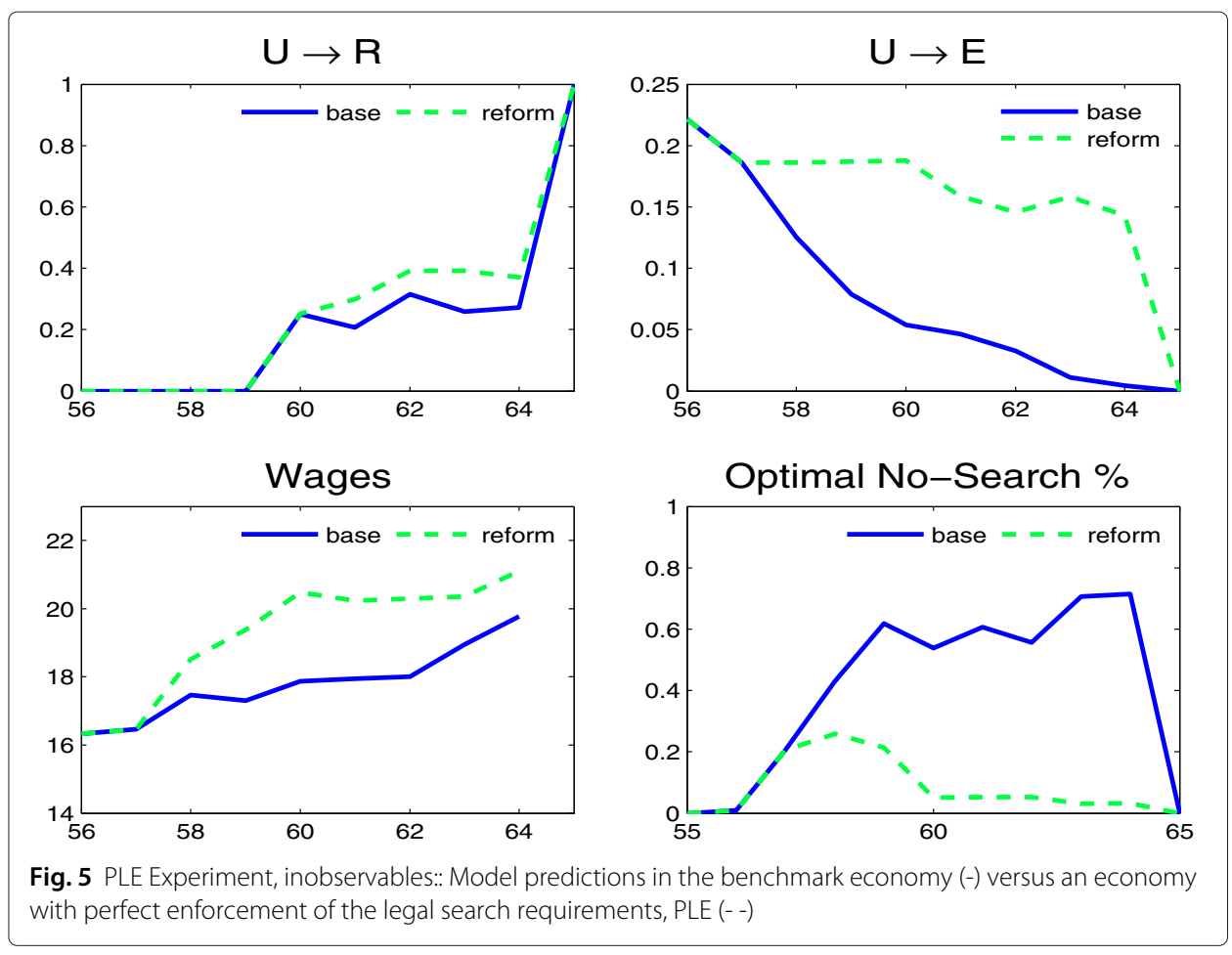

future social contributions paid into the system. The calculation incorporates the optimal individual behavior in each possible labor state and is a function of each person's observable characteristics. The formal definition of the NPC is provided in Appendix C. The total NPC is then converted into an equivalent annuity to facilitate the comparison with the welfare measure used below. In our benchmark simulation, we find that, on average, workers at the beginning of their unemployment spell (ie, with $h=1$ ) are owed 197,000 euros by the public insurance system (NPC1 value in Table 3). This is equivalent to an annual cost of almost 13,000 euros. These values will provide the yardstick to measure the potential financial gains (and welfare impact) of alternative institutional environments in the following sections. Yet before making that comparison, we address the question of whether the widespread resort to non-search behavior will vanish in an environment with more labor-friendly institutions and, more importantly, whether such a change will have a major impact on observed employment rates.

\subsection{Perfect enforcement of the search requirement (PLE)}

According to current Spanish legislation, the collection of the contributory unemployment benefit is conditional on being actively involved in the search for a new job. However, this requirement is hardly ever implemented in practice. This section explores the consequences of a perfect enforcement of this rule. We assume that all the unemployed who decide to stay inactive will receive only the minimum unemployment subsidy, $b_{\text {min }}$, rather than the contributory benefit corresponding to their individual characteristics. This is tantamount to assuming that the system can monitor the decisions of individuals, which, for obvious reasons, is hardly realistic. This is, however, an interesting environment for quantifying the maximum loss of labor supply and pension costs due to the tolerance of opportunistic behavior by the unemployed. 
The experiment's results are reproduced in the 5th and 6th rows in Table 3 and in Fig. 5. Two powerful messages clearly emerge: first, the voluntary choice of non-search behavior becomes rather marginal before the ERA and essentially disappears after the age of 60 . Second, most individuals who preferred to stay inactive in the benchmark will now opt for an active search. This new behavior is specially prevalent among workers with short durations and average or above average pension rights. As a result, average re-entry rates and wages spectacularly escalate (by comparison to the benchmark) in the 58-64 age range. Even when dealing with a remarkably weak labor market for older workers, our simulation predicts a steady re-entry rate of almost $20 \%$ before the age of 60 and of $16 \%$ between the ERA and 65. There is some increase in the incidence of retirement, but its quantitative importance is small. These results suggest that better incentives can potentially generate large efficiency gains in the Spanish case. However, whether all those potential gains can actually be achieved by a real-world reform remains to be seen. The next section seeks to capture some of those gains by changing the pension rules applied to those that access retirement via unemployment.

\subsection{Reform of the pension rules applied when retiring from unemployment}

A key reason why inactivity is appealing in our benchmark scenario is because the individual pension value typically increases while the worker remains unemployed. This is a result of the automatic reduction in the early retirement penalties as retirement is delayed. In contrast, the value of the accrued pension rights tends to diminish, but the former effect is typically greater. As a result, severing this link is a direct way of preventing voluntary inactivity. This can be achieved in a straightforward manner by making the early retirement penalty dependant on the age when the worker stops paying social contributions (rather than on the age when the individual claims the pension benefit for the first time, as is currently the case). This reform amounts to changing the replacement rate $\mu(a)$ in eq. (1) to $\mu(a-h)$. Let us consider, for example, somebody made redundant the day before his/her 60th birthday. If $\hat{w}_{60}$ represents the value of their accrued pension rights, an immediate retirement would result in a pension benefit of $0.65 \times \hat{w}_{60}$. Delaying retirement by one year increases this value to $0.72 \times \hat{w}_{61}$. In contrast, under the new system the incentive to remain inactive while collecting unemployment benefits disappears: after one year, the pension replacement rate will still be $65 \%$ of pension rights. ${ }^{29}$ Unfortunately, eliminating the "perverse" incentives hidden in the current rules comes at a price: a very harsh treatment of the unemployed that search unsuccessfully. We would consequently expect the unemployed with low reemployment prospects to largely self-select into retirement after the reform.

Figure 6 and the bottom rows in Table 3 illustrate the results of this reform. The labor supply consequences are appreciable despite the harsh treatment of unsuccessful searches: the proportion of unemployed workers that opt for searching almost triples in the 60-64 age range, leading to a twofold increase in reemployment rates. These higher re-entry rates also reflects a drop in reservation wages, brought about by a clear erosion of the value of delayed retirement. Searching, however, changes little before the ERA (as there is nothing in the reform to encourage job seeking among those that are simply waiting to claim the pension benefit at 60). The strongest impact is felt, as expected, on retirement (which also sees a twofold increase in its incidence rate). The changes in behavior are concentrated among the short-term unemployed aged 59 or over. Those with 


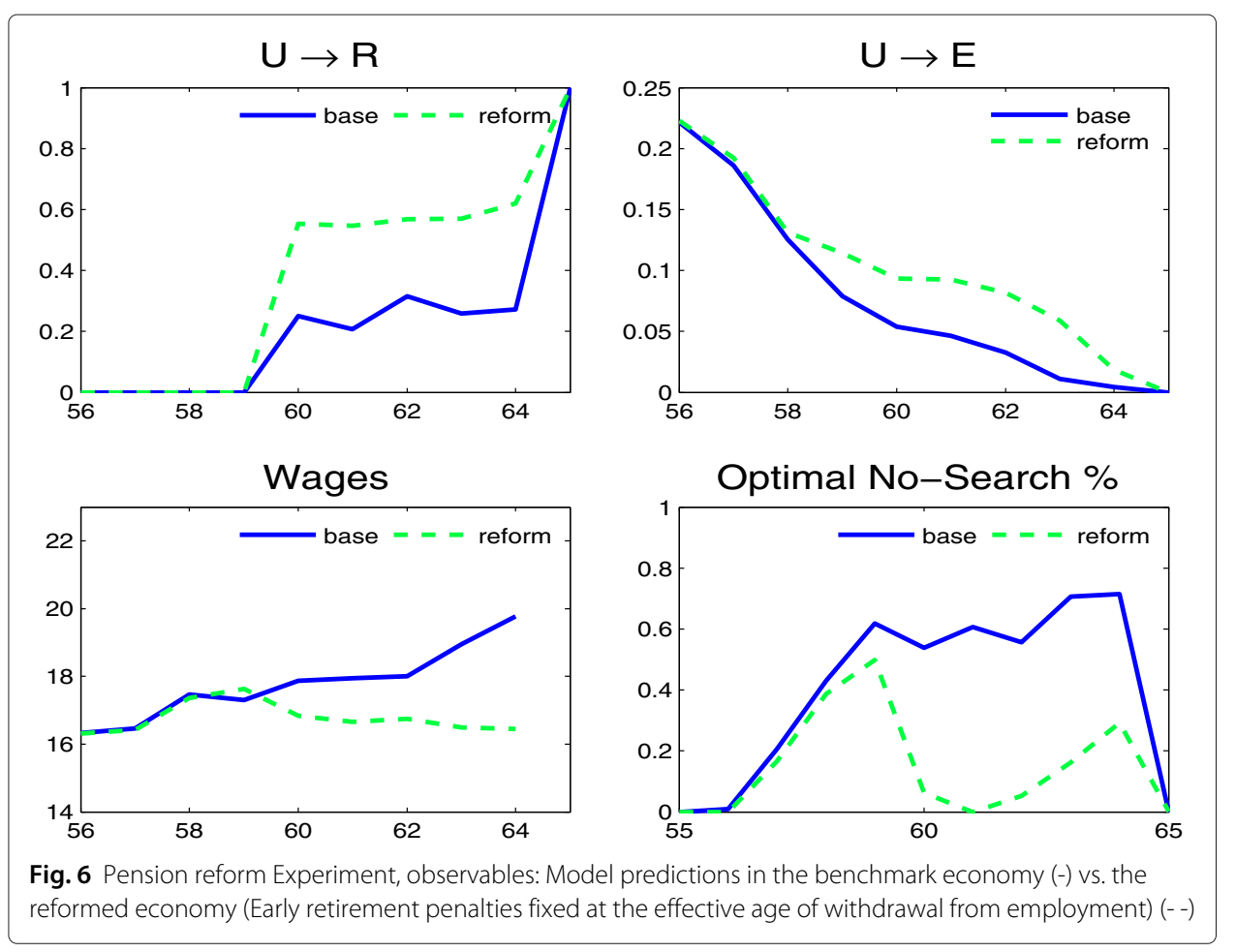

average or below average pension rights tend to intensify their search effort, while those with above average pension rights tend to choose to retire earlier than in the benchmark.

The budgetary consequences of the reform are also very important. In the new environment, pensions are less generous and workers remain in the labor force longer, paying more contributions. As a result, the net financial condition of the combined Social Security system records a rather healthy improvement. On average, each new unemployed person in our sample costs the system 174,000 euros, which is a $12 \%$ reduction from the 197,300 estimated in the benchmark. In terms of the compensating annuity, the average annual savings amount to more than 1,500 euros per worker. Part of these financial gains stems from the extra product generated by all the new employment induced by the reform. Unfortunately, a significant part of these gains also arises from the relatively large pension drops incurred as the duration of the unemployment spell increases. It is therefore essential to explore whether these financial gains are large enough to compensate for the welfare losses the reform inflicts upon some workers.

To test for the possibility of an overall welfare improvement, we compute the Equivalent Variation (EV) associated with the introduction of this institutional change (in relation to the initial benchmark). For each individual, the EV is defined as the income they would be willing to forgo (measured as an annual constant payment) to avoid the introduction of the reform under study. ${ }^{30}$ Table 4 shows the simulated figures. We focus on the results obtained for those at the beginning of the unemployment spell, on the understanding that the change would not be retroactively imposed on the long-term unemployed at the start of the reform.

The reform has a generally negative impact on the welfare of the individuals in our sample; yet the size of the welfare losses is small in most cases. On average, an annuity of 900 euros would be enough to guarantee the initial utility level after the reform. This 
Table 4 Pension reform. Net pension savings and welfare changes (Equivalent Variation for workers starting their unemployment scheme, EV1) from the pension reform. The EV is presented in absolute terms and as a \% of previous wages. Pension savings and absolute EVs are averages by age in thousands of 2002 euros

\begin{tabular}{llll}
\hline Age & Pension savings & EV1 & EV1 (\% previous wage) \\
\hline 55 & 0.12 & 0.07 & 0.37 \\
56 & 0.12 & 0.07 & 0.35 \\
57 & 0.09 & 0.09 & 0.46 \\
58 & 0.16 & 0.03 & 0.10 \\
59 & 1.71 & 0.99 & 3.91 \\
60 & 2.61 & 1.80 & 7.22 \\
61 & 2.30 & 1.39 & 5.80 \\
62 & 2.19 & 1.23 & 5.18 \\
63 & 1.85 & 1.16 & 5.09 \\
64 & 0.85 & 0.62 & 2.94 \\
65 & 0.05 & 0.0 & 0.0 \\
\hline Average & 1.48 & 0.92 & 3.86 \\
\hline
\end{tabular}

is equivalent to, on average, slightly less than (a permanent drop of) $3.8 \%$ of the annual wage earned in the last employment spell. A quite substantial variation in the welfare impact lies behind the average figure. The most important losses are concentrated in the 60-64 age range, peaking at the ERA. For the workers observed at that age, the damage inflicted by the reform is, on average, around $7 \%$ of the previous wage. But the pain is also rather unequally spread according to previous wages and pension rights (figures not shown in the Table). Some workers (those that chose to retire before the reform) avoid losses entirely, while those that choose not to participate in the benchmark are rather heavily hit. In absolute terms, the largest Equivalent Variation occurs among the unemployed with high previous wages and pension rights, peaking at above 3,000 euros. In relative terms, losses are higher among the unemployed with low previous wages and average pension rights (with maximums peaking above $12 \%$ of previous wages).

To explore these heterogenous effects further, Fig. 7 decomposes the welfare losses induced by the reform (and also the associated pension savings) according to the changes in behavior generated. The left-hand panels reflect the impact on workers whose behavior is unchanged, while the right-hand panels reproduce the consequences for workers that change behavior (from non-participation to both retirement and search, and from search to retirement). Note that a few more combinations of choices are possible, but their relevance in our sample is negligible. The sample distribution of the combinations explored is provided in Table 5. Two clear messages emerge from the graphs in Fig. 7. First, workers observed before the age of 58 and workers opting for retirement before the reform are unaffected. All other workers are affected. Second, welfare losses are greater among the unemployed whose previous optimal choice was to remain unemployed without searching.

In principle, the income saved by the pension authorities could be channeled to the workers experiencing welfare losses after the reforms. To explore this possibility, Fig. 7 also shows the net pensions savings generated by the reform (expressed as an annuity and averaged by age). The overall value obtained in the entire sample is 1,500 euros, well above the 0.9 needed to offset the welfare losses. The graphs display where this difference is obtained. For the unemployed whose actions are unchanged, the pension savings 


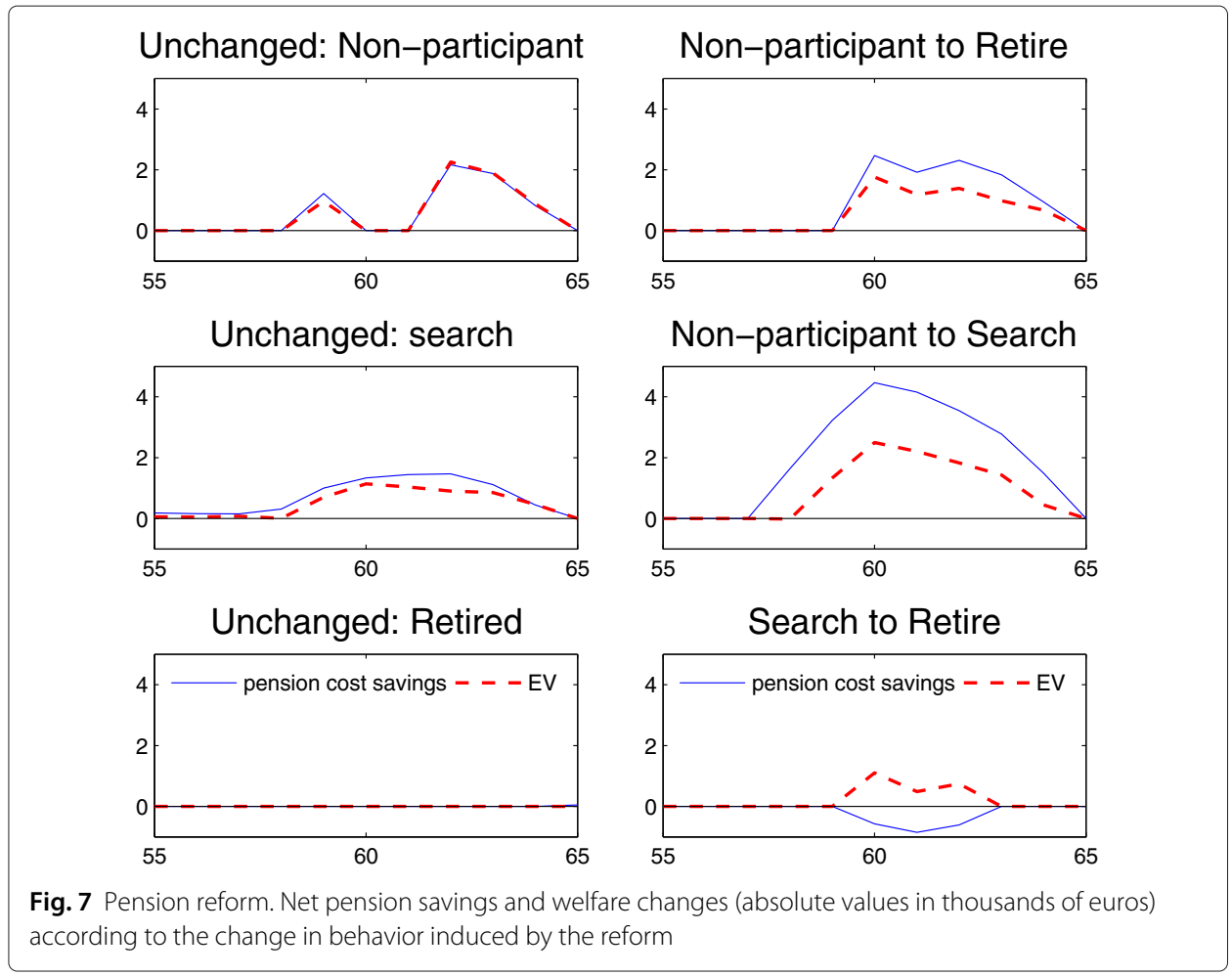

and welfare losses are almost identical. Appreciable differences appear only once behavior has been modified. When the reform leads to shifts from searching into retirement, the result is negative (net pension liabilities increase). These situations are, however, a very small proportion of the total (less than $1 \%$ ). In all other cases, the savings are substantially higher than the compensations (especially when the change in behavior is from nonparticipation to search). Overall, the simulated financial savings achieved by the reform more than compensate for the welfare losses generated. We can conclude that, if the labor market conditions remain unaltered after the reform, the simulated experiment leads to a net welfare improvement.

\section{Conclusions}

This paper studies the relative contributions of bad institutional incentives versus poor labor demand conditions to the meager reemployment rates of Spanish workers aged 55 and over. Seen from an European perspective, the Spanish system of pension and unemployment insurance creates particularly strong incentives for older unemployed workers to remain inactive. This alternative exit route typically implies a two-year delay between the age when a worker effectively stops searching and the age when the pension benefit is formally claimed (collecting unemployment benefits in the meantime). But for households lacking other sources of income, this gap can be much larger (as a result of specific

Table 5 Pension reform. Sample distribution (in \%) of the changes in behavior induced by the reform

\begin{tabular}{lllllll}
\hline \multicolumn{3}{c}{ Unchanged behavior } & \multicolumn{3}{c}{ Change behavior } \\
\hline Prob & RET & Search & NP & NP to Search & NP to Ret & Search to Ret \\
\hline
\end{tabular}


unemployment subsidies). Using a search and retirement model, we have documented the rationality and widespread extension of these phenomena among the unemployed aged 55-67 over the 2002-2008 interval. The prevalence of this practice enhances the welfare of certain specific groups of workers at the expense of the general fiscal burden borne by the Spanish taxpayer. This paper explores a feasible pension reform that effectively terminates the incentive to remain inactive without searching. In our reformed environment, older workers are forced to either intensify their search effort or accept standard early retirement penalties in the event of an early withdrawal. Our simulations predict that this reform generates sufficient pension savings to more than compensate for all the welfare costs incurred. Overall, the paper provides academic support for the convenience of reforms that effectively eliminate the alternative early retirement routes via unemployment (e.g., mirroring the recent legislative changes implemented in Germany and Finland).

Our modeling exercise is only a first step in the greater research efforts needed to understand the interactions of pensions and labor supply behavior at advanced ages. We focused on the (relatively narrow) pre-crisis sample and ignored wealth accumulation and health issues. These simplifications allow for a stationary approach to the problem that renders a numerical solution of the problem feasible. Future analysis should address the aspects that we have excluded from consideration in our first attempt (the role of the business cycle, redundancy payments and the uncertainty created by ever-changing pension rules). By extending the reference sample, our findings will progressively approximate full population predictions. Nevertheless, we view our results as a robust minimum bound on the extension of voluntary non-participation and as a first policy proposal on what action may be taken to mitigate this issue. Another avenue for future improvement involves general equilibrium considerations: our partial equilibrium analysis detaches itself from the impact of institutional changes on prices and labor demand. It is highly unlikely that the induced second-round effects of the reforms would change our qualitative conclusions, but they would most certainly affect our quantitative answers.

\section{Endnotes}

${ }^{1}$ In the 2000-2010 Spanish Labor Force Survey, fewer than $27 \%$ of the unemployed aged 50-54 declared that they were actively seeking a new job. This number fell to fewer than $11 \%$ for those over age 60 .

${ }^{2}$ There is a recent strand of the literature that discusses possible justifications for "Canada Dry pensions" (the authority-sanctioned misuse of unemployment benefits). Some examples are Bhattacharya et al. (2004), Cremer et al. (2006) or Hairault et al. (2012).

${ }^{3}$ In its latest white paper, Commission (2012), European authorities have placed the goal to "restrict access to early retirement schemes and other early exit pathways" at the top of its five recommendations, second only to the task of linking retirement ages to increases in life expectancy. In fact, several countries have recently adopted measures such as restricting the duration of unemployment benefits, extending the supervision of job search activities to the older unemployed, increasing the age limits for the principle of "availability to work" and changing the rules on rejecting job offers for those with unemployment benefits. In countries such us Germany or Finland, the early exit route via unemployment has already largely been closed.

${ }^{4}$ We focus on the Spanish economy, but (as discussed in section 2) we note that other European economies face issues similar to those analyzed in this paper. 
${ }^{5}$ Note, however, that real-world applicability is non-trivial, even in our main experiment. We should account for implementation costs and the difficulty of identifying those targeted for the compensation (unemployed individuals who search but fail to reenter the workforce).

${ }^{6}$ The majority of the population aged 55 or more is out of the labor force. The average unemployment rate was $6.9 \%$ between 2000 and 2010 (according to the Spanish Labor Force Survey), which is well above European averages but smaller than the figure for the rest of the population (8.6\% rate for workers aged 25 to 54). Note also that only a small proportion of the non-participant population in the 50-59 age range classify themselves as retired (only $6.6 \%$ according to the $2000-2010$ EPA).

${ }^{7}$ At the moment, there are 4 people available for work (in the 18-64 age range) for each potential retiree (workers aged 65 or over). This figure is expected to decrease below 1.5 by 2050 .

${ }^{8}$ This statement is true at least for cohorts beginning working before 1967, who constitute the bulk of our sample. Later cohorts have suffered an endless string of increasingly complex pension changes, starting with the 1997 reform.

${ }^{9}$ Disability pensions are another alternative exit gateway, although they have been more strictly monitored in recent times. See, e.g., Boldrin et al. (1999).

${ }^{10}$ The system is rather complex (for a detailed description, see, e.g., Boldrin et al. (1999)), and we abstract some of its relatively minor details. In particular, we do not cover certain tailor-made early retirement routes made possible under the legal figure of a "Special Agreement." Those options are arranged on an individual basis but typically involve some cooperation with employers (sometimes in connection with collective redundancies).

${ }^{11}$ The 2011-2013 reform is progressively increasing the NRA to 67 for most workers. The ERA was increased after the 1997 reform to 61 and then to 63 by the 2011 reform, but because of the long implementation phases for these reforms, these changes do not affect the workers covered by our analysis. The total exclusion of pension and labor earnings is also revised in the 2013 changes.

${ }^{12}$ We do not include a penalty linked to an insufficient number of contributive years (35, which increased to 37.5 in the 2011-2013 reform), which may have a minor effect on the pensions of a small number of workers in our sample. We also ignore the effects of income taxation.

${ }^{13}$ Note that we implement an annual version of the legal formula, which is defined in terms of monthly contributions.

${ }^{14}$ The main difference between these two groups is that workers in the first group are entitled to unemployment subsidies after exhausting contributive subsidies because of a lack of income, whereas those in the second group are entitled only to contributive benefits.

${ }^{15}$ Modeling the interaction of workers and employers clearly demands a paper of its own.

${ }^{16}$ We exclude individuals who are entitled to disability benefits and those with missing information that prevent us from computing their accrued pension rights. Furthermore, we consider only individuals with stable labor market careers (meaning those employed for at least $80 \%$ of their working lives, with fewer than 10 unemployment spells during such time).

${ }^{17}$ There is a significant change in the sample composition around the age of 58 (see Fig. 12 and the discussion in Appendix B). This finding suggests that sample selection may contribute to some extent to the changes in behavior observed before and after that age. However, our theoretical results clearly confirm that a substantial part of the behavior change is a response to the change in incentives around that age.

${ }^{18} \mathrm{~A}$ simple measure of modeling costs is the number of state variables needed for each additional feature included in the model. Here, we managed to handle a model with 4 
state variables (i) by ignoring savings and wealth accumulation, (ii) by confining ourselves to a stationary situation (without business cycle or time variation in public regulations), and (iii) by limiting the sample to healthy workers. The rationale for (i) pertains to the very low levels of liquid wealth observed among workers in the age range considered in the paper. The rationale for (ii) lies in the complacency surrounding those expansionary years that led to widespread forecasting errors. The fact is that including any of those additional factors will come with a hefty price in terms of programing/computing effort and additional data requirements.

${ }^{19}$ Arguably, workers endowed with significant liquid wealth could more easily finance a voluntary unemployment spell. Similarly, the sharp deterioration of market conditions during the Great Recession makes the voluntary unemployment choice more enticing.

${ }^{20}$ Note that our database of administrative records fails to provide information on savings and accumulated assets. We therefore model utility as a function of income (rather than consumption). Empirically, consumption tracks income closely at older ages on average (arguably because most accumulated assets in Spain are illiquid and

households pass them on to future generations). However, we can acknowledge that this feature may be very important for some workers and will be considered in future extensions of this work. Some work on this issue is being conducted by Benitez-Silva et al. (2012).

${ }^{21}$ For the employed, this approximation is exact under the assumption of constant wages.

${ }^{22}$ As noted in our discussion in section 2.1, the unemployment authorities pay the pension contributions on behalf of the worker. Nevertheless, $\hat{w}$ will decrease whenever $\pi$ is less than $\hat{w}$ (for unemployment records of under 2 years) or if $\hat{w}>1.25 \operatorname{minC}$ for longer spells.

${ }^{23}$ Admittedly, there may be some workers who benefit from being made redundant at particular ages. We leave this possibility for future work (as it can only materializes if there is coincidence with the interests of the employer).

${ }^{24}$ In total, we look for six parameters by matching 20 sample moments.

${ }^{25}$ The sample distribution by age, type (with/without unemployment subsidy) and duration in unemployment is presented in Fig. 12 in Appendix B.

${ }^{26}$ The grids are designed to guarantee the presence of a sufficient number of sample observations in each cell on the grid. The resulting grid is the Cartesian product of the following sets (all nominal values are in thousands of 2002 euros):

$\Pi=\left\{\begin{array}{l}8.012 .416 .420 .625 .129 .533 .136 .7\} \\ \hat{W}\end{array}= \begin{cases}7.1 & 10.313 .116 .119 .021 .824 .828 .0\}\end{cases}\right.$

${ }^{27} \eta$ is difficult to pin down because it controls both the degree of risk aversion and the (inverse of the) willingness to substitute income intertemporally. Standard macroeconomic models use relatively low values, in the range between 1 and 4 . See, for example, page 50 in Auerbach and Kotlikoff (1987) or, for econometric estimations, page 31 in Van der Klaauw and Wolpin (2008). The measure and structure of the discount factor is an active area of research, but most econometric estimates in life-cycle contexts tend to produce values close to 1 . An example can be found on page 815 of Rust and Phelan (1997).

${ }^{28}$ We solved several more complex versions of the benchmark model. In particular, we explored models where workers with larger previous wages got higher wage offers (on average). This model matched the observed reentry wages by pension rights better that our benchmark model. The overall fit of the model, however, was not better as the performance in other dimensions deteriorated.

${ }^{29}$ There may still be some incentive to remain inactive for workers with high previous wages and low pension rights. For those workers, the dynamics of $\hat{w}$ may result in pension increases, even with constant early retirement penalties. 
${ }^{30}$ Consider an individual in state $x$. Denote by $U_{b}(x)$ the maximum life-cycle utility achieved by the individual in the benchmark economy and by $U_{r e f}(x)$ the maximum value obtained under the reformed economy. To compute the equivalent variation $\mathrm{EV}(\mathrm{x})$, we first obtain a pure annuity payment, $y_{i}(x)$, that results in the same total life-cycle utility in the two environments considered: $\sum_{a=\tau}^{T} u\left(y_{i}(x)\right)=U_{i}(x) \quad i=\{b, r e f\}$.

We keep all the individual decisions (both in the present and in the future) unchanged in this calculation. The $\mathrm{EV}(\mathrm{x})$ is simply $y_{r e f}=y_{b}+E V(x)$, ie, the annuity payment that, when added to the benchmark annuity, matches the reformed annuity. We interpret this value as the amount of money the individual in state $x$ will be willing to pay to avoid the implementation of the reform (ie, to remain in the benchmark). To evaluate the overall convenience of the reform, we compare the EV with the changes induced by the reform in the net pension cost, expressed as an annuity. Our definition of the welfare measure guarantees that both concepts are defined in a homogeneous way.

${ }^{31} U_{a}^{S}=U_{a}^{S}(\pi, \hat{w}, h), b=b(\pi, h), V_{a+1}^{U}=V_{a+1}^{U}\left(\pi, \hat{w}^{\prime}, h+1\right), \bar{w}_{a+1}=\bar{w}_{a+1}\left(\pi, \hat{w}^{\prime}, h+1\right)$, $E_{a+1}^{W}=E_{a+1}^{W}\left(w, \hat{w}^{\prime}\right), w_{\max }$ stands for the maximum possible wage offer and $\bar{F}(x)=1-$ $F(x)$.

${ }^{32}$ The separation into exogenous vs. endogenous factors is only an approximation as, for example, individual reservation wages also depend on labor market conditions. It serves the purpose of emphasizing that individual specific factors can push workers towards non-participation, irrespectively of labor market conditions.

33 The results are robust to the use of other nonlinear interpolation schemes such as cubic spline interpolation.

\section{Appendix}

\section{A Optimal behavior: theory and simulated patterns}

This section extends the discussion of the behavior predicted by the model. First, section A.1 reviews the theoretical foundations underpinning the choices produced by our model. Section A.2 completes the analysis by exploring some additional predictions of the calibrated model in our simulation sample.

\section{A.1 Optimal behavior by the unemployed}

Before the ERA, unemployed persons' choices were limited to two actions: whether to search or to "non-participate" and, if the worker did search in the previous period and receive a job offer, whether to accept or reject the offer. Here we review the theoretical basis of both choices, starting with the latter.

The decision to accept a job offer For workers approaching retirement, deciding on a job offer is more complex than for younger workers (a choice studied in depth elsewhere in the literature). The key factors for the young unemployed are the unemployment benefit and the option value of waiting for better offers in the future. For senior workers, pension benefits $(B)$ play a progressively more important role, while the relevance of the option value diminishes with age. In all cases, reservation wages summarize the optimal choice. Fig. 8 illustrates the reservation wages predicted by our model for certain selected workers. In general, they depend (see eq. (10)) on comparing the values of employment at each wage $\left(E^{W}\right.$, formalized in eq. (11)) versus the value derived from remaining unemployed ( $V^{U}$, formalized in eq. (5)). The latter, in turn, is a function of:

1. Income sources available outside employment, which are essentially determined by institutional factors: (i) the average size of the insurance benefit $b$; (ii) its 

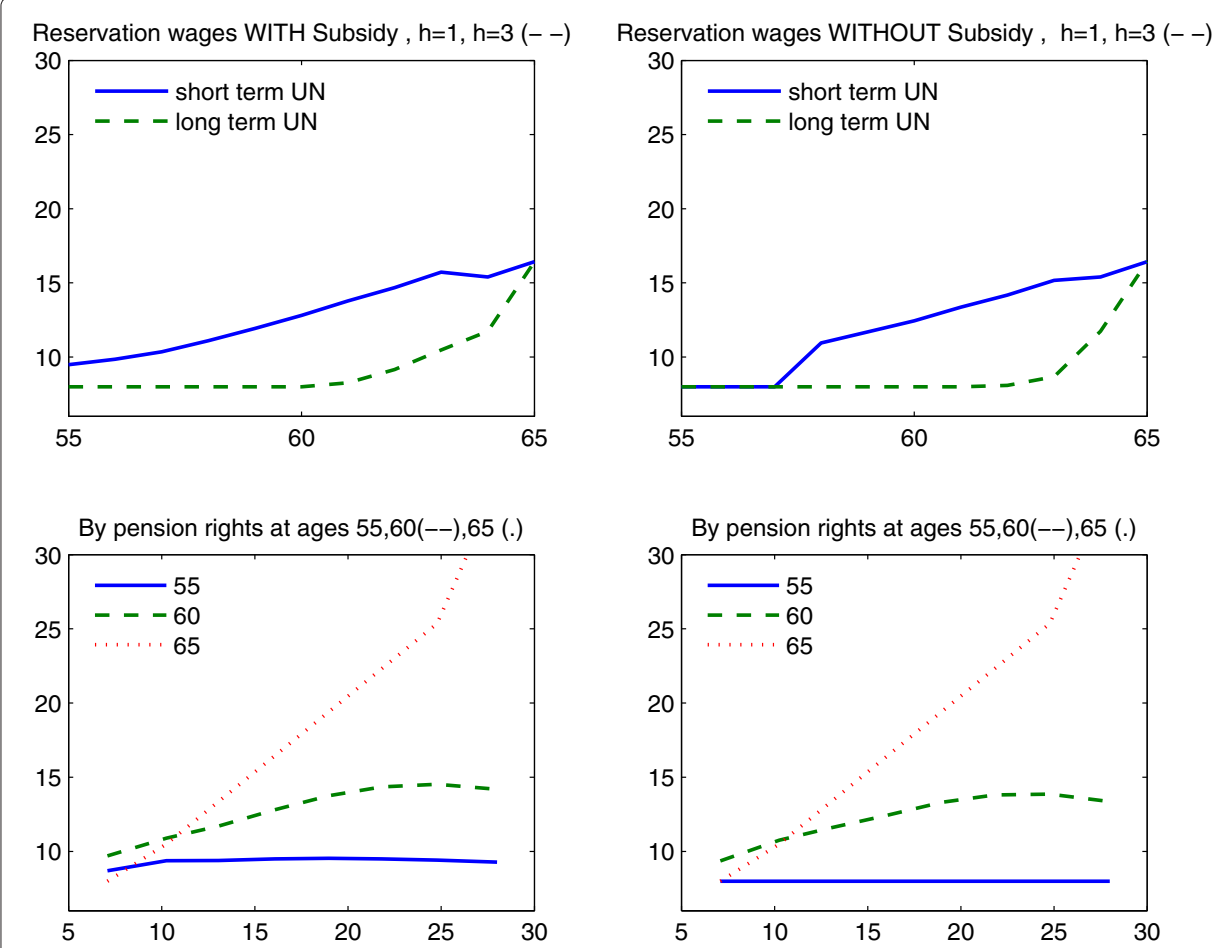

Fig. 8 Theoretical reservation wages by age and duration in unemployment (top panels) and by age and the size of accrued pension rights, in thousands of 2002 euros (bottom panels)

dependence on the duration of the spell, $h$; (iii) its conversion into a welfare subsidy after the exhaustion of the contributory benefit; (iv) the rule applied to update pension rights while unemployed and (v) whether the legal obligation to search is effectively enforced.

Once the ERA approaches, the details of the pension norms (early retirement penalties, $\mu$, and the size of minimum pensions, $b$ min) becomes a progressively more determining factor.

2. The option value depends on external factors (the conditions of the labor market) and worker-specific factors: general employability (reflected in search costs, captured by the value of leisure while searching, $l^{S}$ ) and the individual's risk aversion (i.e., the ability to endure the uncertainty associated with searching).

The value of employment crucially depends on the expected duration of the employment spell. Duration is a function of the firing probability $\delta$ and, more importantly, of age (a link stressed in Hairault et al. (2010)). The large differences observed in reservation wages, $\bar{w}$, before and after the ERA (Fig. 8) clearly point towards age as the more important of the two factors:

1. At early ages (eg. 55), reservation wages are higher among workers entitled to UI subsidies on top of regular benefits (left-hand column in Fig. 8), those with shorter unemployment durations $(\mathrm{h}=1)$ and, to a lesser extent, those with higher previous wages $\pi$.

In general, accrued pension rights are relatively unimportant at those ages. 
2. As workers grow older, the reservation wage increases appreciably. The predicted wage losses after re-entry fall sharply, even becoming negative at the normal retirement age of 65 . More importantly, accrued pension rights $\hat{w}$ become the key determinant of reservation wages (bottom panels in Fig. 8).

The decision to search for a job We approach the search decision in two steps, considering the very different situations faced by workers before and after the ERA. Under the age of 60, retirement pensions are not yet available and the only alternative to searching is to remain inactive without searching. Current income will be the same in both cases, but a job seeker must pay search costs upfront (in the model, as a lower value of leisure). The compensation for that is intertemporal in nature: the worker faces a lottery (an option with a positive expected payoff but which can be rendered worthless at some future stage). The value of this option depends on both endogenous (i.e., individual specific) and exogenous factors. This can be easily appreciated by combining eqs. (8) to (10) to obtain an analytical expression for the search value:

$$
U_{a}^{S}=u\left(b, l^{S}\right)+\beta_{a}\left[V_{a+1}^{U}\left(1-\lambda \bar{F}\left(\bar{w}_{a+1}\right)\right)+\lambda \int_{\bar{w}_{a+1}}^{w_{\max }} E_{a+1}^{W}\left(w, \hat{w}^{\prime}\right) d F_{w}\right],
$$

where we simplify the notation in the text. ${ }^{31}$ By recalling the value of non-participation, $U^{N}$, expressed formally in eq. (7), we can characterize when this is the best possible choice:

$$
U_{a}^{N}-U_{a}^{S}>0 \Leftrightarrow u(b, \bar{l})-u\left(b, l^{S}\right)>\beta_{a+1} \lambda\left[V_{a+1}^{U}(1-F(\bar{w}))+\int_{\bar{w}}^{w_{\max }} E_{a+1}^{W}\left(w, \hat{w}^{\prime}\right) d F_{w}\right]
$$

- The exogenous factors favoring non-participation are related to a non-rewarding labor market with (1) low chances of being offered a job, $\lambda$; (2) a distribution of future wage offers $F$ heavily biased towards small wages and (3) high firing rates (which reduce the value of $E^{W}$ ).

- The endogenous factors favoring non-search are (1) the utility cost of searching $\left(l^{S}<\bar{l}\right)$, (2) impatience, $\beta$, and (3) the value the individual derives from starting the next period as unemployed. The latter acts both directly and through its impact on reservation wages (eq (10)). ${ }^{32}$

All in all, the analysis indicates that non-participation can be the best choice for workers whose skills are in low demand in the market, for those that will incur high searching costs and for those with high current unemployment income and high future pension income.

After the ERA, the retirement option has a very strong bearing on optimal decisions. As the formal analysis is somewhat more complex in that case, we postpone it until we have explored the retirement option against a simpler choice: non-participation.

Non-participation and retirement after the Early Retirement Age To understand the key trade-offs involved in retirement decisions, it is essential to bear in mind that pensions are calculated by multiplying an early retirement penalty and an average of previous gross salaries $(B=\mu(a) \hat{w}$, see eq. (1) and (3)). The value of retirement is simply the present discounted value of the utility derived from pensions (eq. (6)). After the ERA, this value should be compared to the value of non-participation, eq. (7), to determine the optimality of an immediate withdrawal from the labor force (as well as to the value of searching, as indicated below, to cover all possible choices). It is easier to start by considering the 
Duration < 1 year $(\mathrm{h}=1)$

$\begin{array}{llllll}56 & 58 & 60 & 62 & 64\end{array}$

$11111111|1111111 \mathrm{~N}| 11110000|11 \mathrm{~N} 00000| 1 \mathrm{~N} 000000 \mid 00000000$ $11111111|1111111 \mathrm{~N}| 1111 \mathrm{NN} 00|11 \mathrm{NN} 0000| 1 \mathrm{NN} 00000 \mid 10000000$ $11111111|1111111 \mathrm{~N}| 1111$ NNNN | 11NNNN00 | 1 NNNN000 | NN000000 $11111111|1111111 \mathrm{~N}| 1111$ NNNN | 11NNNNNO | 1 NNNN000 | NNN00000 $11111111|111111 \mathrm{NN}|$ 111NNNNN | 1NNNNNNO | 1 NNNNNO0 | NNN00000 $11111111 \mid 111111 \mathrm{NN}$ | 111 NNNNN | 1 NNNNNNO | NNNNNNO0 | NNN00000 $11111111 \mid 111111 \mathrm{NN}$ | 111 NNNNN | 1 NNNNNNO | NNNNNNO0 | NNNN0000 $11111111 \mid 111111 \mathrm{NN}$ | 111 NNNNN | 1 NNNNNNO | NNNNNNO0 | NNNN0000

Duration $>2$ years $(\mathrm{h}=3)$

$1111111 \mathrm{~N} \mid 111$ NNNNN | ONNO0000 | NN000000 | N0000000 | 00000000 $1111111 \mathrm{~N} \mid 111 \mathrm{NNNNN}$ | ONN00000 | NN000000 | N0000000 | 00000000 $1111111 \mathrm{~N} \mid 111$ NNNNN | ONNO0000 | NN000000 | N0000000 | 00000000 $1111111 \mathrm{~N} \mid 111 \mathrm{NNNNN}$ | ONN00000 | NN000000 | N0000000 | 00000000 $1111111 \mathrm{~N} \mid 111 \mathrm{NNNNN}$ | ONN00000 | NN000000 | N0000000 | 00000000 $1111111 \mathrm{~N} \mid 111 \mathrm{NNNNN}$ | ONN00000 | NN000000 | N0000000 | 00000000 $1111111 \mathrm{~N} \mid 111 \mathrm{NNNNN}$ | ONN00000 | NN000000 | N0000000 | 00000000 $1111111 \mathrm{~N} \mid 111$ NNNNN | ONNO0000 | NN000000 | N0000000 | 00000000

Worker without unemployment subsidy

Duration $<1$ year $(h=1)$

$11111111|1111111 \mathrm{~N}| 11110000|11 \mathrm{~N} 00000| 1 \mathrm{~N} 000000 \mid 00000000$ $11111111|1111111 \mathrm{~N}| 1111 \mathrm{NN} 00|11 \mathrm{NN} 0000| 1 \mathrm{NN} 00000 \mid 10000000$ $11111111|1111111 \mathrm{~N}| 1111 \mathrm{NNNN} \mid$ 11 NNNNO0 | 1 NNNN000 | NN000000 $11111111|1111111 \mathrm{~N}| 1111 \mathrm{NNNN} \mid$ 11 NNNNNO | 1 NNNN000 | NNN00000 $11111111|111111 \mathrm{NN}|$ 111 NNNNN | 1 NNNNNNO | 1 NNNNNOO | NNN00000 $11111111|111111 \mathrm{NN}| 111$ NNNNN | 1 NNNNNNO | NNNNNNOO | NNN00000 $11111111|111111 \mathrm{NN}| 111 \mathrm{NNNNN} \mid$ 1 NNNNNNO | NNNNNNOO | NNNN0000 1111111 | 111111NN | 11NNNNNN | 1NNNNNNO | NNNNNNO0 | NNNN0000

Duration $>2$ years $(\mathrm{h}=3)$

$11111111 \mid$ NNNNNNNN | $00000000|00000000| 00000000 \mid 00000000$ $11111111 \mid$ NNNNNNNN | $00000000|00000000| 00000000 \mid 00000000$ $11111111 \mid$ NNNNNNNN | $00000000|00000000| 00000000 \mid 00000000$ $11111111 \mid$ NNNNNNNN $|00000000| 00000000|00000000| 00000000$ $11111111 \mid$ NNNNNNNN $|00000000| 00000000|00000000| 00000000$ $11111111 \mid$ NNNNNNNN $|00000000| 00000000|00000000| 00000000$ $11111111 \mid$ NNNNNNNN | $00000000|00000000| 00000000 \mid 00000000$ 11111111 | NNNNNNNN $100000000|00000000| 00000000 \mid 00000000$

Fig. 9 Optimal labor decisions of the unemployed by age. The structure of the tables and the notation employed is explained in section A.2 
situation of a worker who is certain to retire no later than in the next period, $a+1$, (say at the NRA) and is considering their optimal behavior in this period, $a$. Searching is not an option under those circumstances, and the current choice is only between retirement and non-participation. By adapting eqs. (6) and (7) to this situation, it is easy to formalize the conditions that make retirement optimal $U_{a}^{R}(\hat{w})-U_{a}^{N}(\hat{w})>0 \Leftrightarrow$

$$
\begin{array}{cc}
u(B(\hat{w}), \bar{l})-u(b, \bar{l})>\quad & \beta_{a+1}\left[U_{a+1}^{R}\left(\hat{w}^{\prime}\right)-U_{a+1}^{R}(\hat{w})\right]= \\
\beta_{a+1} \sum_{i=a+1}^{T} \beta^{i-a} S_{a}(i)\left[u\left(B\left(\hat{w}^{\prime}, a+1\right), \bar{l}\right)-u(B(\hat{w}, a), \bar{l})\right]
\end{array}
$$

For most workers, $B(\hat{w})$ is higher than $b$, implying an immediate gain from claiming the pension (i.e., a positive left-hand side above). Waiting one extra year, however, tends to increase pensions, as the gain from smaller early retirement penalties typically exceeds the loss from the updating in $\hat{w}$. This makes $B\left(\hat{w}^{\prime}, a+1\right)$ typically higher than $B(\hat{w}, a)$, resulting in a positive right-hand side. Consequently, only very impatient workers (or riskaverse workers, with a strong aversion to intertemporal substitution) will sacrifice future gains in exchange for current profits.

Relaxing the assumption of definite retirement in the next period $a+1$ or considering the possibility of searching now or in the future, introduces new elements into the calculation, but the essential intertemporal trade-off is unchanged. These new elements have already been discussed (when comparing the choice between search and non-participation before the ERA above) and can easily be adapted to the choices when immediate retirement is possible. For example, for the unemployed with good chances of finding an acceptable job, the relevant comparison is between the current gains from retirement (in terms of income and leisure) versus the possibility of higher income in the future (both while working in a new job and as a result of subsequently higher future pensions).

\section{A.2 The model's in-sample predictions}

Theory alone (at the qualitative level discussed in the previous section) is insufficient to explain observed behavior. Accordingly, we need full quantitative predictions from the model, and this can be achieved only after the model's calibration (assignment of specific parameter values) and numerical solution (as dynamic stochastic models have no closed-form solutions). Section 3.2 is dedicated to the former procedure. Here we briefly elaborate on the latter and complete the information in the main text on the model's quantitative predictions.

The numerical procedure followed to solve the individual problem is fairly straightforward. Numerical value functions are computed by backward induction starting at a maximum working-age $\bar{N}$ (68). At every previous age considered, each value function is solved exactly on a finite grid (whose values are presented in endnote 26). Linear interpolation is used whenever a value function has to be evaluated outside the computational grid. ${ }^{33}$ The optimal decision rules of the unemployed take the form presented in Fig. 9. Each array in these tables reproduces the optimal behavior for a particular age and unemployment duration (h). Each cell in an array is defined by a combination of a previous wage, $\pi$, and a level of accrued pension rights, $\hat{w}$, belonging to the discretized sets $\Pi \times \hat{W}$.

The decision shown in the cell defined by the $i$-row and $j$-column, $d_{i, j}$, is the optimal behavior for the individual whose previous wage is the $i$-th element of $\Pi$ and whose pension rights are given by the $\mathrm{j}$-th element of $\hat{W}$. For the unemployed, $d_{i, j}$ takes the value " 1 " 
when search is the optimal choice; " 0 " if it is optimal to retire; and " $N$ " if non-participation is best.

Finally, we complete the information in the text (the average predicted behavior by age in Figs. 3 and 4) by displaying the behavior when we simultaneously control for the duration of the unemployment spell $h$ (Fig. 10) and for the size of accrued pension rights (Fig. 11).

\section{B Empirical evidence: sample composition at different ages}

In the simulation experiment, we explore the optimal labor flows predicted by our model in a particular empirical sample. As a result, our aggregate predictions are heavily influenced by the sample distribution of individual characteristics (age, unemployment duration, accrued pension rights and previous wages). The changing patterns of these distributions by age (for a given time interval) also reveal certain underlying behavioral regularities. Figure 12 shows some of the properties of this set of distributions, emphasizing the change in tendencies experienced at the age of 58 (i.e., just two years before the ERA). A majority of the workers made redundant at this age can wait till the ERA while enjoying the (generous) contributive unemployment benefit, making them especially susceptible to (informal) early retirement. The graphs show significant changes in the sample composition at that particular age. Before that age, the sample is mostly composed of the long-term unemployed with a relatively low income (making them suitable for unemployment subsidies). By contrast, workers made redundant at the age of 58 have a higher income (both current and career income, as reflected by their accrued pension rights), whereby they are not entitled to unemployment subsidies. The firing intensity is also appreciably higher at 58 and 59, reducing the proportion of long-term unemployed
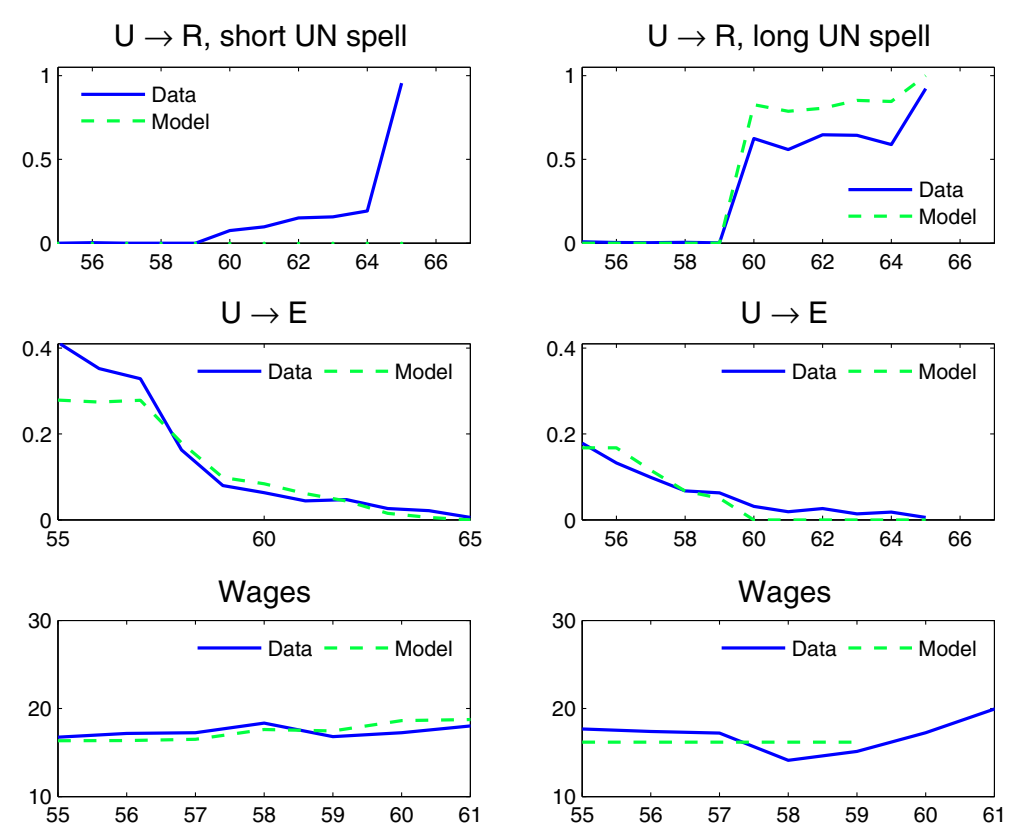

Fig. 10 DATA (blue continuous line) vs. theoretical predictions (green, dashed line) conditional on the duration of the unemployment spell (short, $h<3$, vs long $h=3$ ) 


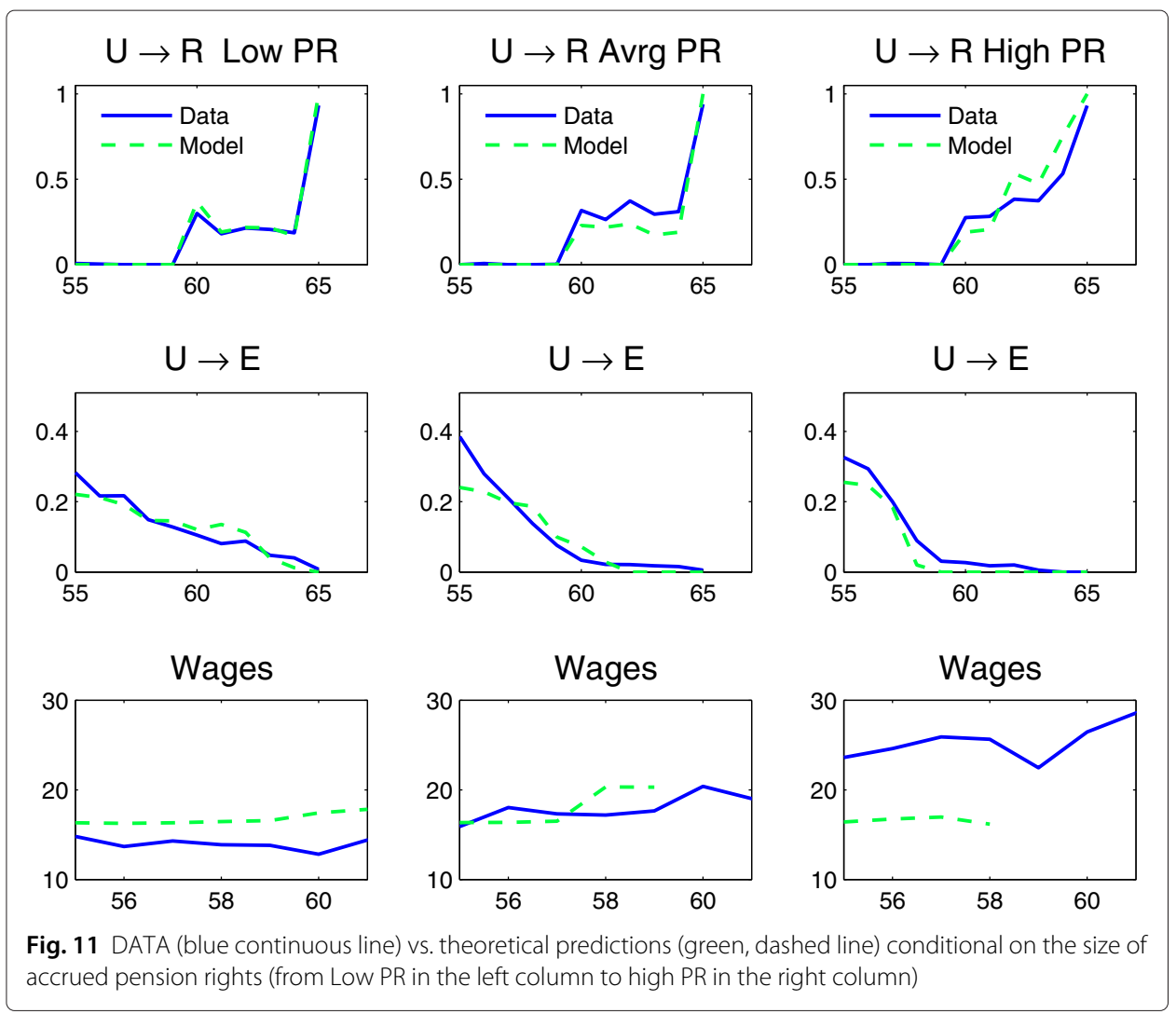

in the sample. It should also be noted that the average reservation wage of certain types of workers increases significantly at the age of 58 (Fig. 13). This is partly the result of changes in behavior specific to that age, although it owes a lot to the change in the sample composition. Studying the possible endogeneity of the redundancy flows at those ages is left for future work.

\section{Pension cost calculation}

We evaluate the total cost each individual represents for the social security system by computing their Net Pension Cost (NPC). It is defined as the expected present discounted value of the flows of transfers received by the individual net of the contributions to be paid to the system. The value is conditional upon the observable state of the individual (age, duration in unemployment, pension rights and previous wages) and is computed recursively.

All flows are discounted to a common age (60) using the same discount factor $(d$, $3 \%$ in our case). In order to draw a comparison with the welfare measure implemented in the paper, the total pension costs are converted into the equivalent constant annual flow (annuity pension cost). The analytical expressions for the total costs are as follows:

- The first value is computed at the maximum retirement age $\mathrm{N}$. The cost implied by an individual observed at that age making the transition from unemployment to retirement is: 

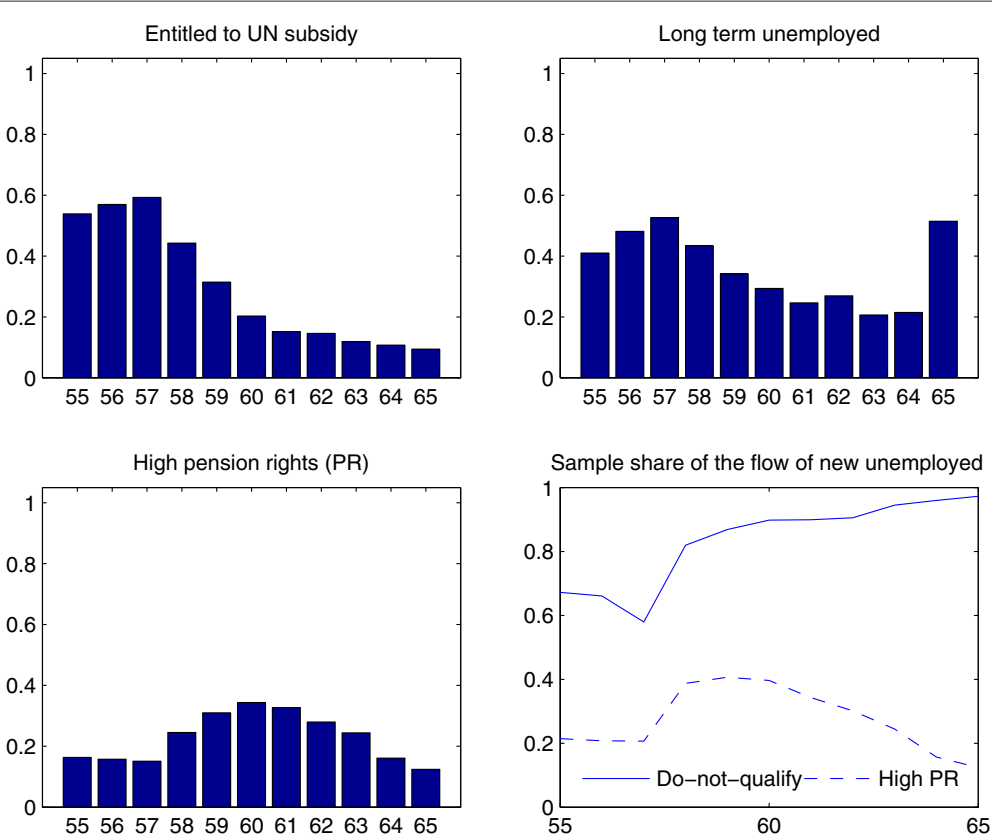

Fig. 12 Distribution of the empirical sample at each age: proportion of the unemployed entitled to subsidy (top left), long-term unemployed (top right) and unemployed with high pension rights, PR (bottom left). The bottom right-hand panel shows the proportion of new unemployed (less than one year duration) without subsidy and with high pension rights (PR)

$$
P C_{N}^{R}(\hat{w})=\sum_{i=t}^{T}\left(\frac{1}{1+d}\right)^{i-60} S_{t}(i) B(\hat{w}, N)=B(\hat{w}, t) A_{N, 60}^{T}
$$

$A_{i, 60}^{j}$ stands for the expected present discounted value of one unit of income received in every period of the age range $\{i, \ldots, j\}$ and discounted to age 60 .

- For individuals observed at the age $\mathrm{N}-1$, the cost associated with retirement, $P C_{N-1}^{R}(\hat{w})$ responds to an expression that is the same as (12). For individuals who remain employed at that age, the implicit cost reflects the contributions paid throughout the year and the change in accrued pension rights:

$$
P C_{N-1}^{E}(w, \hat{w})=-\cot (w) A_{N-1,60}^{N-1}+S_{N-1}(N) P C_{N}^{R}\left(\hat{w}^{\prime}\right)
$$
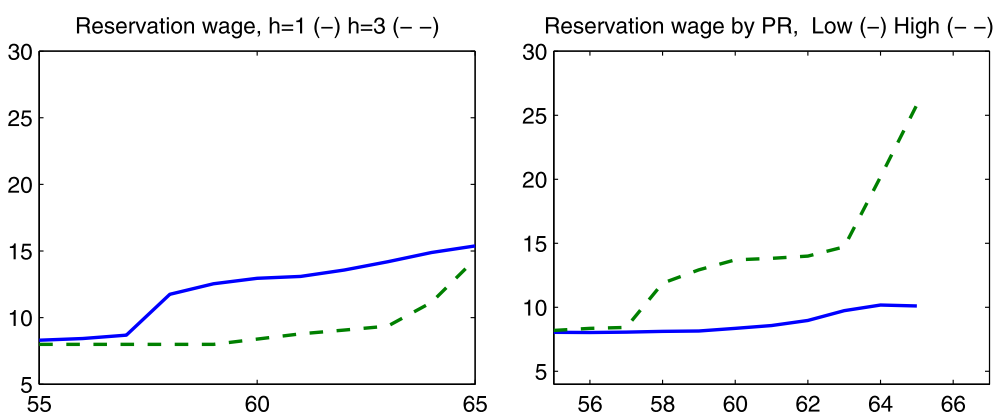

Fig. 13 Average reservation wages by age in the simulation sample 
Pension rights are updated as in (3). Finally, the implicit liability for the unemployed is:

$$
P C_{N-1}^{U}(\pi, \hat{w}, h)=b(\pi, h) A_{N-1,60}^{N-1}+S_{N-1}(N) P C_{N}^{R}\left(\hat{w}^{\prime}\right)
$$

- At earlier ages $t<N-1$, the expressions for the employed and the unemployed become rather cumbersome, reflecting the individuals' different possible behavioral reactions.

- For the employed of age $t$, the implicit cost $P C_{t}^{E}(w, \hat{w})$ is:

$$
\begin{gathered}
-\cot (w) A_{t}^{t}+ \\
+\delta S_{t}(t+1)\left[I_{t+1}^{U}\left(R \mid w, \hat{w}^{\prime}, 1\right) P C_{t+1}^{R}\left(\hat{w}^{\prime}\right)+I_{t+1}^{U}\left(U \mid w, \hat{w}^{\prime}, 1\right) P C_{t+1}^{U}\left(w, \hat{w}^{\prime}, 1\right)\right] \\
+(1-\delta) S_{t}(t+1)\left[I_{t+1}^{E}\left(R \mid w, \hat{w}^{\prime}\right) P C_{t+1}^{R}\left(\hat{w}^{\prime}\right)+I_{t+1}^{E}\left(E \mid w, \hat{w}^{\prime}\right) P C_{t+1}^{E}\left(w, \hat{w}^{\prime}\right)\right]
\end{gathered}
$$

$\delta$ is the exogenous dismissal probability. If the individual is fired at the end of $t$, the individual is unemployed at the beginning of age $t$ with state $\left.x \equiv(\pi, \hat{w}, h)=\left(w, \hat{w}^{\prime}, 1\right)\right) \cdot I_{t+1}^{U}\left(R \mid w, \hat{w}^{\prime}, 1\right)$ and $I_{t+1}^{U}\left(U \mid w, \hat{w}^{\prime}, 1\right)$ are indicator functions taking the value one if the optimal decision is either to retire or remain unemployed. The interpretation of $I_{t+1}^{E}\left(j \mid w, \hat{w}^{\prime}\right) j=E, R$ is exactly the same.

- For the unemployed of age $t$ and state $x=(\pi, \hat{w}, h)$ :

$$
\begin{array}{cc}
P C_{t}^{U}(x)=b(\pi, h) A_{t}^{t}+ & \text { U benefit in t } \\
+S_{t}(t+1) I_{t+1}(S \mid x) P_{t}^{E}(x) E_{w}\left[P C_{t+1}^{E}\left(w, \hat{w}^{\prime}\right)\right]+ & \text { Successful search } \\
+S_{t}(t+1) I_{t+1}(S \mid x)\left(1-P_{t}^{E}(x)\right) C_{t+1}^{U}\left(x^{\prime}\right)+ & \text { Unsuccessful search } \\
+S_{t}(t+1) I_{t+1}(N S \mid x) C_{t+1}^{U}\left(x^{\prime}\right) & \text { Inactivity }
\end{array}
$$

$I_{t}(S \mid x)$ and $I_{t}(N S \mid x)$ indicate the optimality of searching or remaining inactive at age $t$ and state $x$, respectively; $P_{t}^{E}(x)=\lambda(t, h)(1-\Phi(\bar{w}(x)))$ is the probability of a successful search and $E_{w}\left[P C_{t+1}^{E}\left(w, \bar{w}^{\prime}\right)\right]=\int_{\hat{w}}^{\infty} P C_{t+1}^{E}$ $\left(w, \hat{w}^{\prime}\right) d F w$ is the expected value of a successful search. It should be noted, finally, that the value of starting the next period as unemployed is (reflecting the retirement option):

$$
C_{t+1}^{U}\left(x^{\prime}\right)=I_{t+1}\left(R \mid \pi, \hat{w}^{\prime}, h+1\right) P C_{t+1}^{R}\left(\hat{w}^{\prime}\right)+I_{t+1}\left(U \mid \pi, \hat{w}^{\prime}, h+1\right) P C_{t+1}^{U}\left(\pi, \hat{w}^{\prime}, h+1\right)
$$

\section{Competing interests}

The IZA Journal of Labor Policy is committed to the IZA Guiding Principles of Research Integrity. The authors declare that they have observed these principles.

\section{Acknowledgments \\ We gratefully acknowledge the support from research projects ECO2013-43526-R, SEJ-1512, SEJ- 6882 and ECO2014-52238-R. We are also grateful to Dirección General de Ordenación de la Seguridad Social for providing the MCVL data. We thank F. Canova, C. Flinn, JF. Jimeno, C. Michelacci, P. Mira, S. Jiménez, J. Van Ours, T. Crossley and the anonymous referee for their valuable comments; We also thank AJ. Sánchez for his IT assistance and the participants at the ESPE, IIPF, ESEM and CEF annual conferences, the XXXII Simposio de Análisis Económico and the Bank of Spain, CEMFI, FEDEA and UPO regular seminars. The usual disclaimer applies. \\ Responsible editor: Juan F Jimeno}

\footnotetext{
Author details

${ }^{1}$ Department of Economics, Universidad Pablo de Olavide, Ctra de Utrera Km 1, 41013 Seville, Spain. ${ }^{2}$ FEDEA, Jorge Juan 46, Madrid, 28001 Spain.
}

Received: 30 September 2014 Accepted: 13 July 2015

Published online: 13 November 2015

\section{References}

Auerbach A, Kotlikoff L (1987) Dynamic Fiscal Policy. Cambridge University Press, Cambridge, New York Benitez-Silva H, García-Pérez J, Jiménez-Martín S (2012) Incertidumbre de empleo y jubilación en España. análisis comparado y evaluación de reformas. Premio fipros 2011-10, Ministerio de Empleo y Seguridad Social 
Bhattacharya J, Mulligan C, Reed R (2004) Labor market search and optimal retirement policy. Econ Inq 42(4):560-571 Boldrin M, Jiménez-Martín S, Peracchi F (1999) Social security and retirement in spain. In: Gruber J, Wise D (eds). Social Security and Retirement around the world. NBER: University of Chicago Press. pp 305-353

Commission E (2012) White paper: An agenda for adequate, safe and sustainable pensions. Technical report, European Commission

Cremer H, Lozachmeur J, Pestieau P (2006) Desirable misuse of unemployment benefits: The economics of "canada dry" retirement. CORE (Université catholique de Louvain) discussion paper Num 70

García-Pérez J, Jiménez-Martín S, Sánchez-Martín A (2013) Retirement incentives, individual heterogeneity and labor transitions of employed and unemployed workers. Labour Econ 20:106-120

Hairault J, Langot F, Menard S, Sopraseuth T (2012) Optimal unemployment insurance for older workers. J Public Econ 96(5):509-519

Hairault J, Langot F, Sopraseuth T (2010) Distance to retirement and older worker's employment: the case for delaying the retirement age. J Eur Econ Assoc 8(5):1034-1076

Jiménez-Martín S, Sánchez-Martín A (2007) An evaluation of the life cycle effects of minimum pensions on retirement behavior. J Appl Econ 22(5):923-950

Peters M, Dorenbos R, der Ende MV, Versantvoort M, Arents M (2004) Benefit systems and their interaction with active labor market policies. European Commission, DG for Employment and Social Affairs

Rebollo-Sanz Y (2012) Unemployment insurance and job turnover in spain. Labour Econ 19(3):403-426

Rust J, Phelan C (1997) How social security and medicare affect retirement behavior in a world of incomplete markets. Econometrica 65(4):781-831

Tatsiramos K (2009) Unemployment insurance in europe: Unemployment duration and subsequent employment stability. J Eur Econ Assoc 7(6):1225-1260

Van der Klaauw W, Wolpin K (2008) Social security and the savings and retirement behavior of low income households. J Econ 145:21-42

\section{Submit your manuscript to a SpringerOpen ${ }^{\circ}$ journal and benefit from:}

- Convenient online submission

- Rigorous peer review

- Immediate publication on acceptance

- Open access: articles freely available online

- High visibility within the field

Retaining the copyright to your article

Submit your next manuscript at $\gg$ springeropen.com 